\title{
The importance of being modular
}

\author{
PIETER A. M. SEUREN \\ Max Planck Institute for Psycholinguistics
}

(Received 30 November 2003; revised 2I February 2004)

William Croft, Radical Construction Grammar: syntactic theory in typological perspective. New York: Oxford University Press, 200I. Pp. xxviii + 4I6.

\section{INTRODUCTION}

My reason for writing this review article is that I want to highlight a particular basic opposition in linguistic theory and methodology. On the one hand, we have what is usually called CoGNITIVISM, represented in the book under review by the new theory of Radical Construction Grammar, henceforth RCG. On the other hand, there is a variety of schools, together forming a large majority in the field, whose theoretical overlap may be characterized by the term MODULARITY. I argue against cognitivism and in favour of the modularity view, and I am using the book under review as an opportunity to define the issue and put forward the arguments.

The book under review shows more clearly than most other publications emanating from the Cognitive Linguistics camp how serious the consequences are, within a realist framework of language as a faculty of the mind, when the notion of modularity, whether in grammar or in semantics, is abandoned. The result is a relapse into nineteenth-century 'psychological' grammar, reinforced by some early structuralist notions of linguistic analysis and by some (otherwise highly valuable) recent results of cognitive psychology. Since the practice of giving up the notion of modularity is spreading more and more (with California as its main epicentre), it is important to point out the consequences, more particularly because the fact that modularity is so central to modern linguistic thinking has, I believe, not so far been recognized with sufficient explicitness. It is through the consequences of its abandonment that its role and status stand out with greater clarity.

Let me try and define the two positions succinctly in general terms. Cognitivism, it would seem, is defined by the fact that it upholds the following basic principles: (a) it is strongly realist in the sense that it requires psychological reality for linguistic descriptions without any intervening formula of 
interpretation, (b) meaning can be read directly from the surface structure of sentences, without any intervening grammatical or semantic computation, (c) grammar and semantics are accounted for in terms of general cognition, without any form of computational specialization or insulation, (d) virtually all aspects of grammar and meaning are language-specific: whatever is universal in language is restricted to the necessities inherent in the overall genetic make-up of the human species and the physical structure of the world, and (e) semantics is restricted to the psychology of concepts, without any appeal to the philosophy of truth, including logic.

The opposing view, to which I largely subscribe and which has been developed in various schools of linguistics over the past half-century, implies that (a) formal linguistic descriptions are weakly realist in that they must correspond to psychological reality under some formula of interpretation, (b) the codification of meaning in the form of a speech utterance, and also the reconstruction of meaning from incoming speech signals, require a sophisticated computational machinery, specialized for human language and separate from general cognition, (c) the machinery is rapid, algorithmic (and thus automatic) and inaccessible to introspection, (d) it is highly uniform across languages, determining the form of grammars and of semantic structures to a very high degree, leaving only a limited array of choices for each particular language, and (e) the study of meaning requires a philosophical critique of the notion 'truth' and the use of non-trivial formal notions and techniques that are closely associated with logic. Following established terminology, I call the machinery mentioned in tenets (b)-(d) the LINGUISTIC MODULE, and the view of language expressed in these three tenets the MODULARITY VIEW.

In this article, I will limit myself as much as possible to points of grammar, leaving out questions of semantics (though I will be happy to extend my critique to cover points of semantic analysis and description as well). The book under review offers a good opportunity for this mise au point, as it addresses precisely the basic principles mentioned above, focusing on grammar rather than on meaning (p. 62). It presents (pp. 6f., 59) the theory of Radical Construction Grammar as an offshoot of Cognitive Grammar (Langacker I987, I99Ia, b), more refined than another offshoot known as Construction Grammar (Goldberg 1995). The refinement embodied in RCG is motivated by the claim that RCG does a better job in upholding the cognitivist principles (b), (c) and (d) mentioned above, mainly the principle of direct semantic interpretation, without the intervention of any modular, computational machinery.

Implicitly recognizing the empirical and methodological weaknesses of Construction Grammar and Cognitive Grammar, RCG seeks to reinforce the cognitivist theory of language by weakening the notion of linguistic surface structure (it presents 'an impoverished view of syntactic structure'; p. 25), and placing greater emphasis on what are called symbolic and 
semantic relations (p. 25). I argue that even this weakened, or, if one prefers, more refined, version of the 'direct surface-to-meaning' principle fails to do justice to masses of well-known, solid facts of natural languages. If my argument is correct, then it should apply to the 'less refined' versions of cognitivist grammar as well. This makes the book under review an eminently suitable butt for an overall critique of the trend as a whole. Unfortunately, however, the theory proposed in the book is not defined very precisely, which makes a critique more difficult. But we will proceed as well as we can, given the circumstances.

My strategy will be to present a number of observations, mostly from wellknown and well-studied languages, that appear to contradict the principle of direct semantic interpretation and for which the refinements introduced by RCG provide no solace. Pride of place among these observations is given to the facts of German Verb-clustering, which provide the most solid argument in favour of the modularity view that I have ever seen.

\section{A READING}

The book consists of ten chapters. Chapter I (pp. 3-62), 'Syntactic argumentation and Radical Construction Grammar', helped by the first few pages in chapter Io, aims at specifying what Croft's new concept of grammar, RCG, amounts to. The contents of this chapter are discussed in detail below, in section 3 .

Chapter 2 (pp. 63-I07), 'Parts of speech', highlights certain well-known difficulties in defining parts of speech, either within one language or, more seriously, cross-linguistically. The thesis defended (p. 63) is that noun, verb and adjective are not categories of particular languages, but language universals in the sense that 'there are typological prototypes ... which should be called noun, verb and adjective'. The same would apply, one presumes, to prepositions, adverbs, articles and other commonly known parts of speech, though nothing is said to that effect.

Even so, however, one finds that parts-of-speech labels, along with category labels such as NP, VP and the like, are freely used in analysing examples (pp. 2Iof., to take a few arbitrary cases). How does Croft account for his continued use of such labels, despite his contention that they do not correspond to linguistic reality? His answer is that they are labels of convenience, purely 'mnemonic' devices, based on prototypical properties of the corresponding categories. In this he follows Dryer, whom he quotes on p. 50 (Dryer 1997: II8):

Such a choice of label makes it easier to remember the labels and to follow discussions of the language, and it does draw attention to the similarities between these word classes and word classes in other languages. 
This describes the practice that has invariably been followed by linguists since the very beginnings of linguistics. Linguists have always been aware of the fact that, for example, adjectives have different formal properties in the morphology and in the syntax of different languages. Yet they have identified adjectives cross-linguistically on the basis of all kinds of similarities (see, for example, Wetzer (I996) on the universal nature of the category of adjectives), and it is surprising how well this practice has worked through the ages. It does leave, of course, the perfectly valid question of the precise grounds on which word classes and other categories can be and are identified crosslinguistically. And it is one of the merits of modern studies in linguistic typology that this question has been brought to the fore explicitly and with some force. It is, however, unclear what Croft's conception of RCG contributes to answering this question. He just follows Dryer, who sensibly describes, and follows, established practice. Croft does exactly the same, only rather more circumstantially than Dryer and the majority of other linguists.

As regards the 'typological prototypes', little is said in any precise manner, but Croft, roughly, follows Langacker in this respect (p. I04):

Langacker (1987) has proposed a conceptual analysis of parts of speech which is broadly compatible with the universal-typological theory of parts of speech presented in this section. For Langacker, a noun is conceptually a thing, that is, a concept construed as nonrelational and summarily scanned (that is, conceived statically and holistically). A verb is a process, that is a concept construed as relational but sequentially scanned (that is, mentally scanned through time). Modifiers, including adjectives, are concepts construed as relational but summarily scanned.

In Chapter 3 (pp. I08-I3I), 'Syntactic categories and semantic relativity', Croft aims at striking a balance between the universal aspects of meaning on the one hand and the semantic differences found in specific languages. His answer is (p. I28) that there is a universal 'conceptual space', within which specific 'maps' determine semantic structure, which again corresponds to syntactic structure. He assumes a Humboldtian circular flow from conceptual structure to semantic structure to syntactic structure, and back from the syntax to semantics and, again, conceptual structure. He concludes (p. I3I): 'This is what would be expected from a Radical Construction Grammar perspective, in which there are no universal primitive categories'.

Chapter 4 (pp. I32-I7I) is called 'Clausal syntactic roles ("grammatical relations")'. It deals with the question of how to define functional clause constituents, such as subject, (in)direct object, predicate, especially in the context of ergative languages. It should be understood that, in RCG, these 
notions are defined in relation to the whole construction, not in terms of mutual relations. Thus, one may speak of the subject of, say, an intransitive clause, which is a ROLE, but not of the subject of a predicate, which is a RELATION. RCG rejects all relations, accepting only roles - a point that is taken up at some length below. In any case, it is shown that if one applies the distributional method, syntactic roles turn out to be highly idiosyncratic, depending as they do on the constructions in which they occur, which, according to Croft, differ enough, within a language and across languages, to make a categorization impossible (p. I70):

We may now return to the question posed at the beginning of this chapter: are syntactic roles as purely formal grammatical categories more unified in their structure and behavior across languages than the cluster of participant roles that are grouped under each syntactic role? The answer to that question is no. Syntactic roles must be defined constructionspecifically, and the patterns of distribution that they define are varied both within and across languages. Terms such as 'subject' and 'object' do not define some fixed category or syntactic structure. Within a language, there are no categories defined by syntactic role-independent of the constructions they occur in. Instead, constructions are the primitive units of syntactic representation, and the categories they define distributionally are found in relations to each other defined in terms of their meaning or function.

The reader wonders if the problem does not repeat itself for constructions, which are also, by definition, 'construction-specific', and thus unfit to help 'define some fixed category or syntactic structure'. Why it should help to posit that 'constructions are the primitive units of syntactic representation' remains unclear. Equally unclear are the repeated appeals (pp. I32, I59, I60, I6I, I65) to the principles of RCG, which have been presented in chapter I, since it has not been shown how RCG could in any way contribute to a solution. In general, the reader often wonders HOw RCG arrives at the positions formulated or HOw the system is supposed to work. Such questions are invariably left unanswered.

Chapter 5 (pp. 175-202), 'Dependency, constituency, and linear order', discusses the notion of construction and the criteria for defining constructions ('formal groupings'). This chapter is extremely hard to read, even more so than the other chapters, which frequently suffer from the same problem. The problem is that Croft's formulations often fail to make it clear whether he is arguing for or against the positions he describes (see, for example, the discussion around examples (3a-d) below). In any case, the chapter starts with an analysis of the internal structure of a construction (p. I76), which turns out to be a one-to-one pairing of syntactic and semantic structure (more about this below, see figure 3). One understands that there are hardly any SYNTACTIC or FORMAL criteria for the 
identification of constructions. Contiguity is left as the only syntactic criterion (p. 190):

The single cross-linguistically valid syntactic criterion for formal grouping is the CONTIGUITY of elements in the utterance.

Overt morphological marking of dependency relations is considered semantic, rather than syntactic or formal (pp. 199, 202), and linear order criteria are considered invalid ('linear order should be dissociated from the theoretical concept of formal grouping'; p. 197). Thus, for example, A guy [who I hadn't seen since high school] came in and A guy came in [who I hadn't seen since high school] 'are instances of two different constructions' (p. I9I), because of the discontinuity between the antecedent and the relative clause in the latter. ${ }^{1}$ What construction should be taken to be instantiated in the discontinuous case is not made clear. It is recognized that there often are 'mismatches' between syntactic and semantic structure (pp. 199-20I), such as those caused by the discontinuity of constituents, but the reader is not told how RCG accounts for them.

One wonders if this should imply that the ball that hit John and the ball that John hit should be taken to be instances of the same construction, as they differ only in linear order. Or that, given the four strictly synonymous Latin preposition phrases (Ia-d), all meaning 'in the/a big city', (Ia) and (Ib), which differ only in the linear order of the constituents within the construction [adjective/noun], are instances of the same construction, whereas (Ic) and (Id), where the adjective and the noun, respectively, have been placed before the preposition, should be instances of different constructions.

(I) (a) in [urbe magna] in city big

(b) in [magna urbe] in big city (c) magna in urbe big in city

(d) urbe in magna city in big

Chapter 6 (pp. 203-240), 'A radical approach to syntactic relations', argues for the non-existence of syntactic relations, that is, relations between the various constituents of a construction. The only relations that exist are roles, that is, relations between a constituent and the construction as a whole. It starts thus (p. 203):

In this chapter, I will argue that a theory of syntactic representation should posit virtually no syntactic relations. That is to say, the representation of the syntactic structure of a construction should not include any syntactic relations between the elements that make it up. In other words,

[I] Puzzlingly, Croft claims that if these two sentences were to count as instances of one construction, the schematic description of that construction 'would have to say that the position of the Relative Clause is free' (p. 19I). Surely, if it did say that, it would be grossly incorrect on any count. 
the only syntactic structure in constructions is the part-whole relation between the construction and its elements. This is another respect in which Radical Construction Grammar is radically different from other contemporary syntactic theories.

Two paragraphs later one reads:

I am not denying the existence of the formal properties of utterances that were described in $\S 5.4$, such as contiguity, linear order, prosodic structure, and so on. These structures exist, of course. But they are not the manifestation of abstract syntactic relations; they are formal properties of construction types, as instantiated in particular utterances.

One is, apparently, to understand that the 'formal properties of construction types', such as contiguity, linear order and prosodic structure, do not matter for the comprehension of utterances. That, anyway, is what one is given to understand on the pages that follow. On p. 234, for example, Croft says:

The radical approach ... also explains why sentences are interpretable even when the cues provided by coded dependencies go awry (e.g. wrong linear order) or are missing. The coded dependencies are only cues to the symbolic relations in a construction; they are not the glue holding a construction together. The symbolic relations and the semantic relations are the glue holding a construction together.

Apparently, Croft wishes to weaken the notion of surface structure, and thus to alleviate the grammarian's task, by eliminating the need for definitions of a great deal of descriptive apparatus: never mind the fact that the notions cannot be defined, they needn't be, because they are superfluous! Between the two paragraphs quoted from p. 203, the reader is reassured that ' $[\mathrm{t}] \mathrm{here}$ still remains the part-whole structure of constructions. Moreover, the part-whole structure of constructions can be nested'. But will that be enough for adequate grammatical descriptions? We will revert to this question below, and the answer will, not surprisingly, be negative.

Croft's overall intention is to say that one can do grammar largely without form, but not without meaning. Most modern theoretical linguists will say that this is an old conundrum that has now lost most of its relevance, since grammar is seen as a machinery linking semantic (thought) structures with sound representations. That being so, it is obvious that one cannot do grammar without presupposing both semantic structures and phonetic material. Croft reproaches 'componential' grammar for not utilizing 'symbolic relations', i.e. meaning (pp. 205f.), but has to admit (p. 207) that 'the componential model makes up for this deficiency by positing linking rules that link syntactic structures to semantic structures', which makes it 'a notational variant' of construction grammar. What he fails to mention, however, is the fact that in 'componential' grammar models the relation 


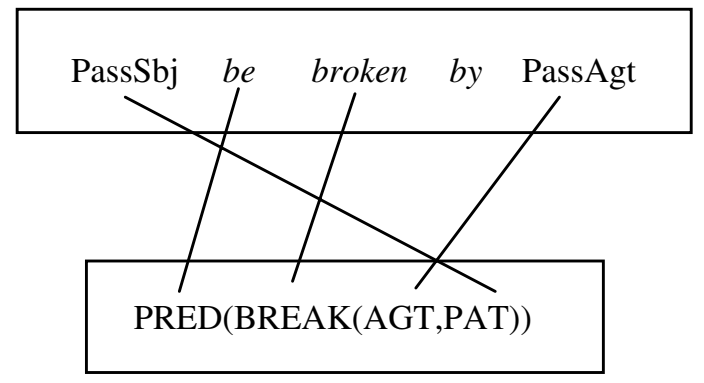

Figure I (=Croft's figure 6.4)

Symbolic links for English Predicated Passive construction

between syntactic and semantic structures is defined COMPUTATIONALLY, not as a one-to-one relation. That is, he fails to mention the MODULAR character of the grammar models he wants to criticize. That difference, of course, involves more than mere notational variation.

The alternative proposed in RCG results in endless taxonomies. For example, the sentence The window was broken by the neighbor's kid (pp. 2I5f.) is analysed as in figure $\mathrm{I}$.

Just above this figure one reads that in RCG 'there is no subject syntactic relation as such'. But it would seem that there is no systematic, semantically defined subject ROLE either, since what is the subject of this passive construction has a very different role in the corresponding active construction. Croft will probably reply that he distinguishes between subjects in active and passive constructions, just as in chapter I (p. 55) he distinguishes between a Transitive Verb category and an Intransitive Verb category:

Thus, the Transitive Verb category in the Transitive construction and the Intransitive Verb category in the Intransitive construction can be subsumed under a more general category, which I will call Morphological Verb.

In the same way, he could subsume Active and Passive Subjects under a more general category of Subjects. But when will this continuing unification of categories stop? The standard answer, which is also the correct answer, is that it will stop the moment one ceases to regard a grammar as a taxonomy and starts regarding grammar as a system of rules. The taxonomy then becomes a mere epiphenomenal by-product that will be of interest in all sorts of studies of language use but not in the theory of grammar. The RCG answer appears to be that endless taxonomies are automatically avoided if one drops most of the descriptive apparatus.

What else does this chapter offer? Lots and lots of examples from all sorts of languages, all purporting to make the same points and all giving rise to the same questions. 
Chapter 7 (pp. 24I-280), 'Heads, arguments, and adjuncts', aims at showing that heads, arguments and adjuncts are not syntactic but symbolic relations. The same questions that have been raised before rear their heads again here, and the answers are missing here as they were before.

Chapter 8 (pp. 283-3I9), 'The voice continuum', is a small monograph on voice, mostly active and passive, with some discussion of ergativity, but without any reference to medium or reflexive-intransitive. It concludes (p. 3I9):

All of the universals in this section ... are formulated without reference to any universal structural definition of any voice type. Instead, the concept of a syntactic space was introduced to represent the full cross-linguistic syntactic diversity of voice constructions (in fact, only a subset of that diversity). Using the conceptual space model and the universals of the coding of function into form introduced in $\S 2.4$, we are able to discern universals of grammatical voice while at the same time accommodating the full range of syntactic diversity of the world's languages.

The relevance of this chapter to RCG is marginal, and I will spare it any further discussion. The same goes for chapter 9 (pp. 320-36I), "The coordination-subordination continuum', a small monograph on the ways clauses and other construction types can be combined into coordinated or nested structures. Since no conclusion is drawn that has a specific bearing on RCG, I will refrain from any further discussion. ${ }^{2}$

Then there is the short, final chapter Io (pp. 362-368), 'Syntactic theory and the theory of language'. It opens with the words (p. 362):

In this book, I have presented the case for Radical Construction Grammar. I have argued that virtually all aspects of syntactic structure are language-specific, indeed, construction-specific.

But what has been SHOwN in the preceding chapters is only that some aspects of syntactic (and morphological) structure are language-specific and, indeed,

[2] I must make an exception for Croft's way of dealing with serial verb constructions (SVCs) in this chapter. They are 'defined' as follows (p. 323): 'A serial verb construction is a construction containing two or more verbs which appear to be integrated into a single clause to some degree.' This would make, for example, the German Verb-cluster hätte kaufen wollen in the clause weil ich es hätte kaufen wollen (because I would have liked to buy it), or the French construction exemplified in Il est allé boire (he has gone drinking), instances of SVC, since there are three verbs fully integrated into a single clause! The discussion of a small number of alleged instances of SVC on pp. 352-354 is lax and derivative to a degree that defies critique. Serious attempts at defining SVCs, such as Sebba (1987) or Seuren (1990), are not mentioned, probably because they involve formal, i.e. modular, grammar. This is a great pity because SVCs are a prime example of a construction that is (a) precisely definable in terms of universal grammar, (b) limited to certain (groups of) languages, and (c) subject to prototypical restrictions on verb selection. This combination should be extremely appetizing to any typologically oriented theoretical linguist. 
construction-specific. Most of the topics dealt with stand out for their language-specific and construction-specific properties, and no linguist that I know would deny those facts. But there is no ARGUMENT other than rhetoric for rejecting any theory that implies strongly determinant universal properties of grammatical structure, as RCG does. And this rhetoric lives by ignoring those aspects of grammatical structure that have been shown, over the past half-century, to be strongly constrained, if not fully determined, by universal properties of human language, and, in particular, by universal properties of the formal grammatical computational system that defines form-meaning mappings for each specific language.

The chapter then contains a summary, in five points, of RCG, which is said to be 'disarmingly simple' (p. 362), and 'just a syntactic theory' (p. 364). The five points are (pp. 362f.):

I. 'The only type of primitive grammatical units are CONSTRUCTIONS - pairings of form and meaning which may be atomic or complex, schematic or substantive. ... There are no atomic schematic elements - syntactic categories. Syntactic categories are defined within (complex) constructions, that is, as schematic elements playing a role in some construction.'

2. 'The only type of syntactic relations within a construction are the MERONOMIC (part-whole) relations between the construction on the one hand and the ELEMENTS that fill the ROLES of the construction. Since syntactic roles are defined relative to constructions, there is no universal finite inventory of syntactic role types.'

3. 'A construction joins its form and meaning via symвolic relations.'

4. 'One type of generalization within languages are categorizing relations, referred to above. A second type of generalization is found across constructions and across languages. These are systematic patterns of variation, such as PROTOTYPES and IMPLICATIONAL HIERARCHIES, that characterize cross-constructional and cross-linguistic diversity and constrain the distribution and even the form of constructions used for particular functions (chapters 2, 4, 8, 9). That is, valid cross-linguistic generalizations are generalizations about how function is ENCODED in linguistic form. Moreover, the variation within and across languages is governed by the same generalizations.'

5. 'The patterns described above are accounted for by the hypothesis of a largely universal CONCEPTUAL SPACE (Chapters 2-3) which represents structures in the human mind. Distribution patterns are overlapping SEMANTIC MAPS on conceptual space. Language universals are accounted for by constraints on the TOPOGRAPHY of conceptual space which predict what sort of patterns can be found within and across languages, and what sorts of diachronic grammatical changes may occur.'

The chapter closes with a summary rehearsal of Croft's ideas about language change and language evolution as published in Croft (2000). 


\section{A Discussion}

Let us go back to chapter I, where one finds, to begin with, an expatiation on a set of questions that have been well-known in linguistics for half a century, all of which are connected with the notion and methodological role of DISTRIBUTIONAL ANALYSIS as first introduced by Zellig Harris around I950. In Croft's view, the method of distributional analysis is basic to all contemporary linguistic thinking (p. 4):

Radical Construction Grammar is also radical in that it goes back to the foundations of syntax in order to make this new beginning. The reason why we must discard all of the formal apparatus is a fundamental flaw in the use of the basic method of empirical syntactic argumentation used in linguistics. This method, the DISTRIBUTIONAL METHOD, defines syntactic categories in terms of their possibility of filling certain roles in certain GRAMMATICAL CONSTRUCTIONS. ${ }^{3}$

And again (p. II):

There is essentially one single, simple, method that is widely used for syntactic analysis. This method is called DISTRIBUTIONAL ANALYSIS.

Croft then proceeds to show (pp. 29-47) that, on this premiss, distributional analysis leads to a quandary caused by the fact that no two elements have exactly the same distribution under any system of categorization in any language, which makes it hard to establish syntactic categories. Moreover, once categories have been established for one language, as a result of 'methodological opportunism', a further appeal must be made to this 'opportunism' to establish cross-linguistic categories, such as those of noun, adjective, adverb, or subject, direct object, etc., which all have non-identical distributions in different languages. Therefore, established linguistic methodology is at fault and RCG will put things right.

The first thing a professional linguist will say, at this point, is that this quandary has been well-known since at least the I950s. It was precisely the reason why the inductive method of distributional analysis meant to yield socalled DISCOVERY PROCEDURES was abandoned as a method for discovering correct linguistic analyses and replaced with the deductive method of the formation and testing of descriptive hypotheses. That is, one just posits categories for each specific language and assigns them certain structural and/or semantic properties, and one then sees to what extent the machinery (or module) $M$ that is based on them yields the right results, according to an agreed set of eliminative adequacy criteria. These criteria require, first,

[3] Croft's use of the term roles in this sentence is misleading, given his specific use of the term. It would have been more adequate to speak of positions, which reflects the standard notion of distribution. 
observational adequacy: $M$ must not yield incorrect results. Then there is predictive adequacy: $M$ must predict correct results that have not so far been observed, and must do so for the language as a whole. At this level it is required that $M$ captures significant generalizations within a given language. Then follows the criterion of cross-linguistic adequacy: $M$ must, as much as possible, fit into a universal linguistic schema that is formulated in such a way that cross-linguistic generalizations are maximized and the differences among specific languages are minimized. At this level it is required that $M$ be constrained by the universal schema mentioned, which can be considered part of a general theory of human language. Here also, linguists worry about the universal properties of the categories posited for each specific language. Further, higher adequacy criteria may be invoked, which will integrate linguistic theory into a wider scientific context.

There is, however, no mention at all, in the entire book, of the deductive method. All one finds is the following, somewhat startling, passage (pp. Iof.):

It has been suggested to me that the methodological question is of relatively minor importance. In particular, reference is made to Chomsky's argument that it is unreasonable to ask linguistic theory for a discovery procedure for identifying the right grammar for a particular language (Chomsky 1957: 50-3). However, the problem which I am referring to is more basic than that. It is what Chomsky calls the condition of generality (ibid., 50), necessary for any adequate theory of grammar: "we must characterize the form of grammars in a general and explicit way so that we can actually propose grammars of this form for particular languages' (ibid., 53-4). That is, for a particular language we can argue for and thus justify the analysis of that language's structures as an instance of the structures found in Universal Grammar.

It is the condition of generality that I believe current syntactic theories fail. That is, the methods that linguists use to argue for their syntactic theories carry hidden fallacies which are largely unremarked upon. When these fallacious assumptions are uncovered, their abandonment leads us to a very different approach to syntactic theory than that advocated by formalist theories and even the functionalist syntactic theories referred to above.

Croft might have mentioned that widespread failure to meet the "condition of generality' was precisely the reason why the inductive discovery method was abandoned, fifty or so years ago, in favour of the deductive method. Do current syntactic theories fail on the score of generality, as Croft says they do? Well, to the extent that they are still searching and have not reached definitive final results, one may say that they have failed. Croft, however, appears to posit that current syntactic theories are destined to fail forever, because their methods 'carry hidden fallacies which are largely unremarked upon'. One understands that the first step RCG takes to put things right is a 
reversal to the inductive discovery method, squarely based on distributional analysis. Our curiosity has, of course, been raised, as we would like to see a problem analysis that shows (a) why current syntactic theories are doomed to fail on account of their fatal 'hidden fallacies', and (b) why a reversal to the inductive discovery method can be expected to be more successful while any hidden fallacies that would lead to persistent failure are avoided. Croft does make a number of attempts to show why current syntactic theories are doomed to fail, but these are all based on the assumption that these theories follow an inductive discovery method, which they do not (p. 29):

... distributional analysis is also a method that has been used for UNCOVERING Universal Grammar, that is, syntactic categories and roles that are found across languages ... (emphasis mine)

Meanwhile, one wonders how RCG itself aims at achieving theoretical adequacy in linguistic descriptions while applying the inductive method of distributional analysis.

According to Croft, it is inherent in the distributional method, which he professes to follow steadfastly, that the 'basic units' of syntactic description and analysis are constructions, not the elements that make up constructions (p. 4):

The distributional method and the linguistic facts it describes turn out to be incompatible with the assumption that syntactic structures or constructions are made up of atomic primitive syntactic elements, that is, the elements that make up the building blocks of other syntactic theories.

Instead, constructions are the basic units of syntactic representation, and categories are derived from the construction(s) in which they appear - as the distributional method implies.

Why the 'basic' status of constructions over their constituent elements should FOLLOW FROM the distributional method is enigmatic. It certainly does not follow from Harris's original (195I) notion of distributional analysis, which is based on the purely inductive maximizing of collocational schemata. One may, of course, start from larger units (constructions) and describe these in terms of their constituent elements, as Harris proposes at the end of his book (I95I: $365-373$ ). But this is then no longer bottom-up distributional analysis but its opposite, top-down generative grammar, in the simple form of a phrase-structure rewrite system. ${ }^{4}$

In any case, RCG should be taken to be centrally characterized by the claim that 'constructions are the basic units of syntactic representation, and categories are derived from the construction(s) in which they appear' (p. 4),

[4] See Seuren (1998: 227-229) for a detailed discussion of how the final pages of Harris (I95I) presage the notion of a generative grammar and how, historically speaking, they actually led to it. 
that is, by 'the primitive status of constructions and the nonexistence of primitive syntactic categories' (p. 5). This gives rise to a number of questions, among which we count: How are constructions to be characterized or defined? How are they stored in the mind? How are they acquired? The answers given in RCG are essentially taxonomic, with an appeal to the psychology of categorization. The implication appears to be that the only way of generalizing over constructions is by means of "the general cognitive process of CATEGORIZATION' (p. 4). Yet how the analysing linguist should apply this general cognitive process of categorization to his or her material so as to arrive at the proper analysis in terms of constructions is left open (pp. 4f.):

There are several reasons for not examining categorization in detail in this volume, besides the practical issue of length. First, a full treatment of this issue must await further psychological research and its application to language. ... Nevertheless, the search for maximally general categories and rules for a particular language will not yield what its practitioners believe. Maximally general categories and rules are highly likely not to be psychologically real (see § I.3.3); hence the search for maximally general analyses is probably a search for an empirically nonexistent - that is, a fictional - entity. Moreover, constructing a maximally general analysis inevitably leads to the ignoring of empirical fact - namely, the manifold differences in distributional patterns of different constructions and categories. In other words, maximally general analyses are fictional in a second sense, in that they do not represent empirical reality.

But this, one fears, is nothing but rhetoric. Croft argues for his point of view by making the false allegation that 'constructing a maximally general analysis inevitably leads to the ignoring of empirical fact', and by appealing to psychological research that has not been done. Cf. also p. 53:

The best way to understand how to identify constructions is to use the results of psychological research into categorization and the formation of taxonomies, a domain that regrettably will not be discussed in this book.

However, as we were told on p. 5, such results do not, or not yet, exist. This appeal to psychology must, therefore, be considered vacuous.

But that is not all. While insisting on p. II, quoted above, that ' $[\mathrm{i}] \mathrm{t}$ is the condition of generality that I believe current syntactic theories fail', Croft states here, on p. 5, that 'maximally general categories and rules are highly likely not to be psychologically real' and speaks of 'a search for an empirically nonexistent - that is, a fictional - entity'. It is difficult to reconstruct what Croft actually intends to say. Does he uphold maximization of generality as a descriptive ideal, which 'current syntactic theories' fail to achieve, or does he reject that ideal, thereby shaking the foundations of scientific 
methodology? Croft refers the reader to section I.3.3, which tells us that there is a 'taxonomic network of constructions', where each construction constitutes a 'node' (p. 25):

Any construction with unique, idiosyncratic morphological, syntactic, lexical, semantic, pragmatic, OR discourse-functional properties must be represented as an independent node in the constructional network in order to capture a speaker's knowledge of their language. That is, any quirk of a construction is sufficient to represent that construction as an independent node.

'Grammatical information', Croft argues (p. 28), can and should be 'redundantly represented in the taxonomic hierarchy'. For that reason, he supports a 'usage-based' model of syntax, resting largely on the premiss that 'a high token frequency of a particular word form or syntactic construction will lead to the storage or ENTRENCHMENT of that word form or construction' (p. 28). Further down that page one reads:

The usage-based model holds out the promise of a psychologically principled way to determine which constructions of a language should be independently represented as nodes in the taxonomic network, that is which constructions are actually entrenched in a speaker's mind.

One fears that Croft's optimism is in need of some dampening. What he proposes looks very much like a Linnaean taxonomic approach carried over to linguistics: instead of a systematic listing of each unique plant and animal species and subspecies, Croft envisages a systematic listing of each unique grammatical construction. But grammatical constructions are not like animal or plant species or subspecies. They are the result of identifiable grammatical processes whose results are found in sentences that normally manifest a combination of constructions, besides any number of lexical or other idiosyncrasies. For example, the sentence John is likely to want Harry to send Florian away combines the following constructions (depending on one's grammatical theory): 3 rd person present singular copula (is likely), Subject-to-Subject Raising (John), Subject Deletion (John), Subject-to-Object Raising (Harry), and Particle Extraposition (away). One may, of course, try and make an inventory of constructions, as traditional grammars usually do. But it should be done sensibly. What Croft proposes is to treat (2a) and (2b) as different constructions because the former has the particle to whereas the latter does not. And (2c) is seen as a different construction again, because it disallows a passive counterpart *Harry is wanted by John to send Florian away.

(2) (a) John caused Harry to send Florian away.

(b) John made Harry send Florian away.

(c) John wants Harry to send Florian away. 
But this makes for total confusion. It is much more sensible to treat all three as instances of the Subject-to-Object construction and attribute the absence of to in (2b) to a lexical idiosyncrasy to be listed with the verb make, and treat the absence of the passive for (2c) either as a lexical idiosyncrasy associated with the verb want or as a consequence of a general principle yet to be formulated, which predicts the absence of passives for certain predicates.

Moreover, even if one makes a sensible inventory of all constructions in a language, that does not mean that there is no room for a formal, general theory that will impose constraints on possible constructions, just as Linnaean taxonomy does not preclude deeper, more generalizing analyses. These, as one knows, have led to the discovery of DNA structure. In like manner, one feels that theoretical linguists should have the liberty to carry out deeper analyses leading to generalizations in the postulated rule systems.

Croft fails to address the massive literature that has appeared over the past forty or so years, showing that there is no significant relation between token frequency and the internal organization and structure of linguistic competence. It is true that usage-based notions of grammar have become quite popular over the past I5 years, especially among computer linguists, functionalists and in stochastic optimality theory. But these branches of linguistics either do not strive for theoretical adequacy or, like RCG, simply fail to address the existing literature. In the present context, the question is whether each speaker's linguistic competence has the form of a 'taxonomic network of constructions' exclusively or predominantly constrained by tokenfrequency effects. Croft maintains that it does. I agree with Newmeyer (2003) that it does not: there is overwhelming evidence that competence is organized as a rule system, not as a taxonomy. ${ }^{5}$

Let me give just one simple example, taken from real life. Some years ago I observed a father with his young son who was crying. The father said: 'Welleducated boys don't cry', whereupon the boy retorted 'I didn't educate me, Yoú did!' The remarkable feature of the boy's reply, apart from its quick wit, is, of course, the fact that he did not use the reflexive pronoun myself, which would have conveyed the wrong meaning, but the non-reflexive me, which conveys the meaning intended. I think that Croft, or anyone else, will be hard put to maintain that this particular construction had occurred with sufficient token frequency in the boy's linguistic experience to be entrenched in his

[5] This does not preclude the view that the rule system that forms each speaker's linguistic competence is subject to frequency effects and, more generally, to functionality conditions. There can hardly be any doubt that it is, at least to some extent, though opposite forces are also at work (Seuren 2004: section 5.7). For example, speakers in a position of social prestige often indulge in linguistic affectations to manifest their position. These affectations may take the form of a specific pronunciation, the preferred use of specific expressions, the introduction of morphological irregularities, etc. Often such affectations find their way into the language not by their frequency or their functionality, but, on the contrary, by their special, marked character as manifestations of group membership. 
taxonomy of constructions. Much more plausible is a rule-based account, which analyses the contrastively accented I didn't educate me as being derived from an underlying cleft construction 'not [be I [the $\mathrm{x}$ [x educated me]]]', with [be I] as the main predicate. In this structure there is no reason why me should be reflexivized, since it is not coreferential with the subject term of its clause, that term being the variable $x$. But that means that the boy must have developed an internal rule system which does the derivation for him. And it can do so only in a modular way.

Once one looks at the empirical reality of language there is an inexhaustible supply of such examples (some are given in Newmeyer 2003). RCG, far from 'respect[ing] the grammatical diversity of languages, and the uniqueness of each language's grammar' (p. 33), irredeemably fails to do so. The observations, discussed below, relating to German Verb-clusters and other constructions in various languages add to this conclusion. Modular, rulebased accounts score significantly better.

It is, moreover, rather hazardous to maintain that 'maximally general categories and rules are highly likely not to be psychologically real', as such a statement violates the sacred methodological principle known as Ockham's razor. As long as the speaker's mind remains a closed box (and that is what it is in this class of cases), one has no choice but to go by the simplest hypothesis, that is, the hypothesis that carries the widest generalizations while accounting for all the known facts. And the modular, rule-based hypotheses are the ones that score best in this respect, as is demonstrated vividly by the case of the German Verb-clusters, discussed below. Psychologists do not deny that, but they add that speakers usually have, in addition to their modular grammar, a large memory-stored fund of useful formulations and manners-of-speaking (including idioms), which can be called upon by way of short-cut whenever that is convenient. And listeners, as far as can be ascertained given the present state of the art, tend to proceed via the method known as 'reconstruction-by-hypothesis': utterance meaning is grasped by an early identification of lexical items, which are placed in a cognitively plausible semantic structure, constrained by whatever formal means exclude multiple readings. This provisional structure is then tested for grammatical correctness by running it through the top-down grammar module so that remaining ambiguities are eliminated as much as possible (see Seuren 2004: section $3 \cdot 5 \cdot 5 \cdot 2$, and the references quoted there).

The next issue in need of discussion is what is meant by 'the primitive status of constructions'. This, one reads on p. 5, 'makes Radical Construction Grammar a NONREDUCTIONIST theory of syntax', a notion that is further elaborated on p. 47, where Croft claims:

The main conceptual hurdle to considering Radical Construction Grammar as a logically possible theory of grammar is the assumption that the primitives of syntactic theory must be atomic. 
For Croft, '[t]heories in which the primitive theoretical constructs are atomic are REDUCTIONIST theories', while '[t]heories in which the primitive theoretical constructs are complex are NONREDUCTIONIST theories', the paradigm example of a non-reductionist theory being the theory of perception proposed by Gestalt psychology (ibid.).

This again calls for some comment. The distinction between atomic and primitive elements makes sense only in the context of formal theories. In formal theories, the so-called primitive or axiomatic elements are those symbols that do not occur as definienda, that is, on the left-hand side of the $'={ }_{\text {def }}$ ' sign. It is often a matter of notational choice or internal organization whether one takes this or that element as primitive, as long as the system works the way it is meant to work. Atomic elements, on the other hand, are those elements that are not assigned any internal structure by the formal theory in question. Whether an element is atomic or complex is not a matter of notational choice or internal organization but of theoretical substance. It is common for atomic elements to be non-primitive (i.e. defined in terms of primitives), and vice versa, for primitive elements to be non-atomic (complex). This makes it odd to suppose that any theory of syntax should labour under the false 'assumption that the primitives of syntactic theory must be atomic'. In fact, this assumption is not made in any of the formal syntactic theories known to me. In the case of RCG it cannot be made, nor can it be rejected, because RCG is not a formal theory by a long shot.

It would seem that the use of these terms is out of place in the context at hand. Gestalt theory has never been formalized, so that it makes no sense to speak of 'atomic' or 'primitive' elements there. (What Gestalt theory says is that perception requires as end result a meaningful, integrated mental structure, in terms and in function of which constituent parts of distal stimuli are (re-)interpreted.) Generative grammar, on the other hand, has been subjected to a certain degree of formalization. There it is a matter of notational choice whether one takes symbols like 'S', 'NP', 'VP' as primitive or as defined by their constituents. But there is no doubt as to the atomic status of the so-called 'terminal' symbols, which usually represent morphemes or words.

What Croft actually means when he claims that RCG is a 'nonreductionist' theory, or that constructions are 'basic' or 'primitive' while the constituent elements are derived from them, is far from clear. What is clear is that RCG wants to do away with certain accepted notions in the theory of grammar, in particular (p. 5) with the notions of 'primitive syntactic category' and 'syntactic relation'. But how are these to be identified in other theories, so that we know what Croft proposes to do away with? What does he mean by 'primitive syntactic category' and what by 'syntactic relation'?

As regards 'primitive syntactic categories', one understands from p. I3I that what is meant is 'universal primitive categories', and these include (p. 4) 'two of the most fundamental sets of categories posited by syntactic 
theories: parts of speech such as noun and verb, and syntactic roles ("grammatical relations") such as subject and object'. But that is not all. On pp. 2of., it is intimated that what other theories call S, VP, NP, PP, etc., that is, names of construction types, should also be eliminated from linguistic theory. Thus, whereas more current grammatical theories, such as the various forms of generative grammar, analyse a sentence like Heather sings syntactically as $\left[[\text { Heather }]_{\mathrm{NP}}[\text { sings }]_{\mathrm{VP}}\right]_{\mathrm{S}}$ (we will forgive Croft the missing separate V-label for [sings]), RCG analyses the same sentence syntactically as [[Heather] [sings]], i.e. with identical constituent structure but without labels such as S, NP, VP (or V). If any labels are to be attached, they will have to be much more idiosyncratic than the ones used in generative grammar and other theories.

And as regards 'syntactic relations', the relevant text on p. 5 runs as follows:

All of the aforementioned syntactic theories posit the existence of SYNTACTIC RELATIONS between the syntactic elements in a construction, such as between a subject noun phrase and a verb, or between an attributive adjective and a noun, although the theories vary significantly in exactly how syntactic relations are represented.... Radical Construction Grammar does not posit any syntactic relations in constructions. The only internal syntactic structure to constructions is their MERONOMIC or part-whole structure: the syntactic structure of constructions consists only of their elements (which may also be complex constructions) and the ROLES that they fulfill in the construction.

Naturally, a host of questions arises immediately, such as Why?, How?, What is gained?, not to mention the question What is lost?, because the elements that Croft apparently wants to see removed from the notion of construction, such as linear word order (see above), are clearly constitutive of what is called well-formedness, and hence of the data used for the description of languages.

One should note that syntactic RELATIONs like subject and predicate are saved from extinction as long as they don the guise of syntactic ROLEs. The distinction is explained on p. 24, in relation to the intransitive construction exemplified by Heather sings:

The term 'Subject' can mean one of two things. It can describe the ROLE of a particular element of the construction, that is, a PART-WHOLE Or MERONOMIC relation between the element labeled 'Subject' in the Intransitive construction and the Intransitive Construction as a whole. This is the sense in which one says that Heather is the Subject of THE INTRANSITIVE Clause Heather sings. ... The term 'Subject' can also describe a syntactic RELATION between one element of the construction - the Subject - and another element of the construction - the Verb. This is the sense in which 


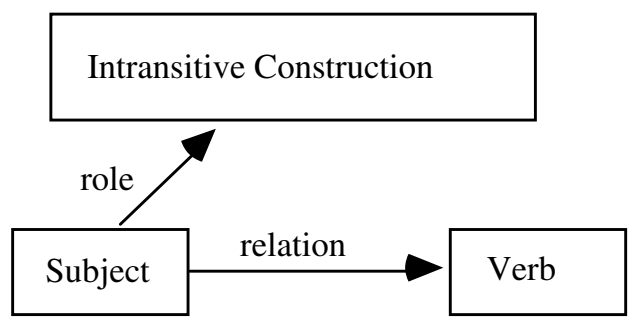

Figure 2 (=Croft's figure I.Io)

The difference between syntactic roles and syntactic relations

one says that Heather is the Subject OF THE VERB sings. As noted above, the Subject syntactic relation is assumed to be manifested by a variety of properties, such as the case form of the noun phrase (in English, with Pronouns), agreement of the Verb (in English with 3rd Person Subjects in Present Tense), and word order (in English, preverbal position).

And again on p. 220:

Syntactic roles relate a syntactic element to the whole construction, while syntactic relations relate a syntactic element to another syntactic element. ... [I]f one posits syntactic roles (as well as symbolic relations), then one can dispense with syntactic relations.

A graphic representation of the distinction is given on p. 24, our figure 2.

The syntactic roles are then given a clean bill of health, and the syntactic relations are exiled. That is, it is legitimate to speak of, for example, the subject of a clause, but not of the subject of a verb. The sYNTAX of constructions, it is repeated over and over again, is largely arbitrary and ad hoc. Any system in syntactic constructions is imported by their semantics, which in all languages requires linear contiguity of the constituent syntactic elements (p. 190) and probably also a unifying intonational contour (pp. I9If.), and which may be supported, depending on the language, by some form of morphological coding manifesting the constructional (that is, semantic) dependencies. Even so, it is accepted that one finds 'mismatches' (pp. 199-20I), as in the case of discontinuous constituents or unexpected morphological marking. ${ }^{6}$ Information (topic-comment) structure,

[6] The Latin Gerundive Construction would probably count as a morphological mismatch. An instance of this construction is the preposition phrase de litteris scribendis, consisting of the preposition de 'about', which assigns ablative case to the noun litteris 'letters', and hence to the attributive gerundive adjective scribendis 'to be written'. This phrase has not only the regular, expected meaning 'about letters to be written', but also the unexpected meaning 'about the writing of letters', which one would expect to be rendered as *de scribendo litteras, with the same preposition de, followed by the ablative form of the infinitive scribendo 'writing', which again is followed by the regular accusative for the direct 


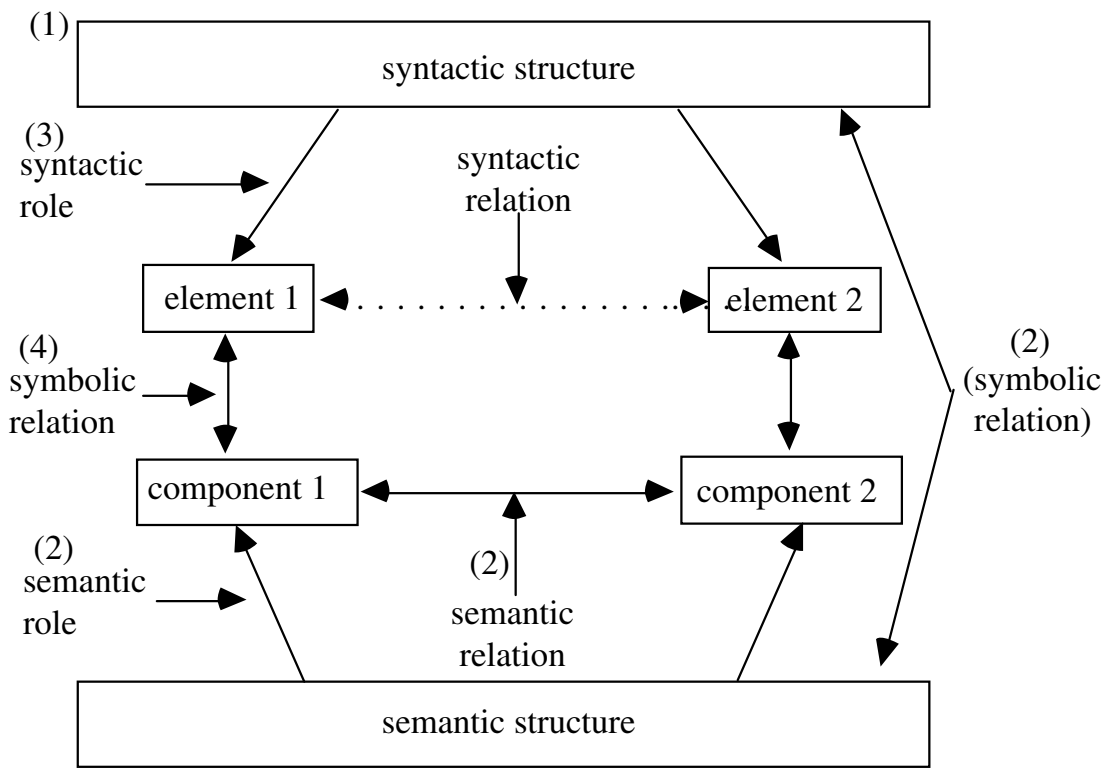

Figure 3 (=Croft's figure 5.I)

The internal structure of a construction (exploded diagram)

moreover, may override the normal expression of predicate-argument structures (p. 20I), although the relation between 'normal' syntactic structure and information structure remains totally opaque.

I find this hard to understand. How does Croft intend to justify the removal of criteria such as the linear position of words or constituents, or secondary case assignment (for example the assignment of accusative case to a semantic subject, as in (3c) or (9) below), which are central to the notion of well-formedness - unless he is prepared to tamper with the criterion that grammars should describe linguistic competence? Alarmingly, as we will see in a moment, this appears to be just what Croft does, despite his proud declaration (p. 33) that RCG 'allows each language to be itself: it respects the grammatical diversity of languages, and the uniqueness of each language's grammar.' What RCG seems to respect more is a linguistically incompetent speaker's measure of freedom to put grammar aside and improvise.

To see what is going on we must have a closer look at what is meant by the term CONSTRUCTION in RCG. The answer is given on p. 176 in a figure, reproduced here as figure 3 .

object litteras 'letters'. However, the phrase *de scribendo litteras is ungrammatical in Latin, even though scribendo litteras 'by the writing of letters' is perfectly correct. 
The reason why syntactic relations are represented by a dotted, and not a solid, line is that they are considered not to exist. The corresponding diagram without the dotted line is found as figure 6.I on p. 204 (I have taken over from figure 6.I the bracketed numbers (I)-(4), whose role will become clear presently). We understand, therefore, that, for example, the English Predicated Passive construction shown in figure I above consists of the four elements PassSbj, be, broken, and by + PassAgt, some of which are subconstructions. Each of these four elements is then related to a semantic 'component' by means of a symbolic relation, and each such component has a semantic role in a corresponding semantic structure. Moreover, the various semantic components are related to each other by semantic relations. Any alleged corresponding syntactic relation is thereby superfluous, since whatever work might be done by a syntactic relation is already done by the corresponding semantic relation. The same should hold, one would expect, for morphological constructions, but nothing is said about the 'reality' of such morphological relations, which, by the same token, should be declared unlawful as well.

It should be observed, in this context, that the semantics envisaged in RCG largely follows the trend, which has spread from California over the past fifteen years or so, to reintroduce folk psychology, laced with a selection of results of modern psychological research (whose independent value is beyond doubt), but ignoring not only all work done over the past half century in formal semantics but also all seminal and cogently relevant work done in philosophy over the past 150 years. There is a great deal of talk, especially in the later chapters, about conceptual, semantic and even syntactic 'space', about Gestalt properties, about figure-ground distinctions, but no semantics, because the basic notions are missing.

Croft's account of how the process of comprehension takes place is a prime example of simplifying folk psychology, worth quoting in full. Starting from the diagram of his figure 6.I (which is identical to figure 5.I reproduced above as figure 3 but without the dotted arrow for the banned syntactic relations), he says (pp. 204f.):

Consider the situation of a hearer with his grammatical knowledge organized as in Figure 6.I. The hearer hears an utterance; for communication to succeed, the hearer must arrive at an understanding of the meaning conveyed in the utterance. The process of understanding can be described in four steps, indicated as I-4 in Figure 6.I (these steps are not necessarily sequential, of course).

In Step I, the hearer recognizes the utterance as an instance of a particular construction. That is, the hearer is able to identify the box labeled 'syntactic structure' in Figure 6.I as the syntactic structure of a particular construction. In Step 2, the hearer accesses the semantic structure of that construction in his or her memory via the symbolic relation between the 
syntactic structure as a whole and the semantic structure as a whole. By this step, the hearer also accesses the semantic components and semantic relations between components. In Step 3, the hearer identifies the elements of the syntactic construction via the syntactic roles of the construction. Finally, in Step 4, the hearer utilizes the symbolic relations to identify the appropriate semantic component corresponding to each syntactic element.

That is, the hearer has now understood what the speaker has said-the overall semantic structure plus the components of that structure-without any recourse to syntactic relations. And understanding the meaning of an utterance is the goal of communication. Syntactic relations are not necessary to achieve this goal.

This passage is remarkable for a number of reasons, one reason being the startling assumption, discussed above, that constructions and their meanings are stored in memory, without a word of comment on the vast body of literature, and the corresponding tradition, of the past fifty years precisely denying that assumption and replacing it with a system of combinatorial and transformational rules. Another remarkable feature is the apparent identification of, on the one hand, the type-level process of grasping the meaning of a sentence in virtue of the form-meaning mapping system of the language in question, and, on the other, the integration of the sentence meaning into any current token discourse and token situation the uttered sentence is about - a distinction already well-known in European structuralist semantics (see, for example, Antal I964).

But rather than subjecting this passage to further scrutiny, I want to raise the question of what is actually gained by all this. In the light of the seriously lacking formal specification it hardly makes sense to ask if there is any crucial POSITIVE EVIDENCE, that is, any data that fail to follow from existing theories of grammar, where they can only be accommodated as idiosyncrasies or listed as counterevidence, but which naturally follow from the RCG approach. But fortunately, it still makes sense to ask if there is any NEGATIVE EVIDENCE, phenomena that do occur in language but cannot be accommodated in terms of RCG or any related theory. We shall see in a moment, when discussing the Subject-to-Object Raising construction in English and the German Verb-clustering construction as exemplified in (9), that RCG appears to rule out large classes of constructions that are common in natural languages. Such constructions constitute at least a challenge, but more probably counterevidence, to RCG and thus pose a problem for it.

Croft might answer, not without reason, that understanding an utterance is not the sort of algorithmic process that is to be described in terms of a formal system, but rather a stochastic process relying on all sorts of linguistic as well as non-linguistic cues, whose complex interaction it is hard, if not 
impossible, to capture in a formal system. In fact, something like this answer is given on pp. 2IIf. Having discussed some examples of quantifier floating and of morphologically rather involved possessor and relative clause constructions in a variety of languages, Croft turns to the difficulty such phenomena pose for his notion of construction-driven form-meaning mapping and comments as follows (pp. 2IIf.):

In the above cases, it would be difficult to identify a semantic relation corresponding to the putative syntactic relation. But if we abandon the assumption that there is a syntactic relation, the remaining syntactic structure - the part-whole relation - is iconic with the semantic structure. And there is no insuperable difficulty for the hearer to figure out the semantic relations. The hearer can find the possessor or quantifier easily enough in the possessor ascension and quantifier constructions, and also identify the NP argument to whose denotation the possessor referent or quantifier applies. Likewise, the hearer can find the controller of the anomalous agreement pattern.

Here, however, we must raise some serious objections. First, such an answer is inconsistent with what is said in the passage quoted earlier from pp. 204f., which does not invoke any external, non-linguistic support for the comprehension process, drawn from situational or encyclopedic world knowledge and allowing for the construction of plausible scenarios. On the contrary, the comprehension process is treated there as being entirely selfcontained and construction-driven, that is, compositional.

Then, if RCG has no better purpose than to describe the hearer's guessing of what a speaker must have meant, then what will keep a competent listener from understanding a sentence like I believe him to have eaten the bagel (p. 2I3; quoted as (3c) below) as meaning 'I believe him when he says that he has eaten the bagel', i.e. in a control, rather than a raising, interpretation? Note that an analogous interpretation is possible for the sentence She helped him go bankrupt, which is ambiguous between the raising reading 'she collaborated with others in bringing about his bankruptcy' and the control reading 'she assisted him in bringing about his own bankruptcy'. It is indeed 'easy enough' for a speaker of English to understand what is meant by someone who says Me not water in. Me no can swim! But are these constructions of English? Of course not. If Croft is serious about his claim (p. 33) that

[RCG] allows each language to be itself: it respects the grammatical diversity of languages, and the uniqueness of each language's grammar

then the answer that the hearer can find the required semantic relations 'easily enough' simply won't do. It takes much greater linguistic competence to produce an utterance like Please don't make me go into the water. I can't swim! than it takes to comprehend the two garbled sentences quoted above, 
for which only a limited amount of competence is needed, plus, of course, a great deal of general practical knowledge.

If a grammar is meant to be a description of linguistic competence in a language $\mathbf{L}$, then what is wanted is a model describing the ability of a competent SPEAKER of $\mathbf{L}$ to produce grammatically faultless and semantically adequate utterances, not a model describing a competent HEARER's ability to make sense of utterances that may be grammatically and/or semantically defective, or the ability of a not so competent hearer who succeeds in making sense of a well-formed utterance despite his or her defective knowledge of the language. The hearer provides data for a description of linguistic competence in so far as (s)he provides the linguist with judgments on lexical, grammatical, phonological and phonetic correctness of given utterances in terms of a given language, dialect or sociolect.

Croft's Step I in the comprehension process ('the hearer recognizes the utterance as an instance of a particular construction') is the main stumbling block, as it is unclear HOw the hearer recognizes specific constructions. Given the very large array of possible constructions in the postulated taxonomic network of constructions (p. 25), and given the realistic possibility that some construction, such as the construction instanced by $\boldsymbol{I}$ didn't educate me discussed above, has not yet been firmly entrenched, what will keep a hearer from misunderstanding an instance of this construction? A hearer may, for example, misinterpret the utterance as 'I didn't educate myself'. Yet a competent hearer does not do that, even though the utterance is not an instance of a well-entrenched, known construction. The question is: how does a competent hearer achieve such a feat? RCG does not give a satisfactory answer, but rule-based grammar models do. Their answer is that the hearer has internalized a rule system which PREDICTS the correct interpretation of the utterance in question on the basis of formal clues and top-down grammarchecking, as has been indicated above.

\section{Immediate Construction-Meaning Association}

Croft's notion of construction as explained above is based on a principle which I will call the Immediate Construction-Meaning Association, or ICMA Aхіом, and which can be defined as follows, as much as possible in the spirit of RCG:

\section{The Immediate Construction-Meaning Association (ICMA) Axiom}

Each syntactic construction is directly associated with a semantic structure (stored in memory along with the syntactic construction) without the intervention of formal (transformational), logical or mathematical operations on the tree structure.

The Axiom thus rules out not only any form of Transformational Grammar but also any form of mathematically defined functional application as 
current in Categorial Grammar, or any form of lambda-abstraction or lambda-conversion as current in various forms of grammar associated with Montague-type model-theoretic semantics.

The principal rationale behind the ICMA Axiom seems to be the consideration that stronger versions of it, in particular the ONE-FORM-ONEMEANING PRINCIPLE, are too strong and fall foul of too many facts in too many languages. Croft seems to expect that a weakened form of direct form-meaning association, where 'form' is restricted to 'construction' in his sense, will be sufficient to account for the data, so that 'formalisms' can still be avoided, a goal that is apparently considered important.

Croft's position, defined in the ICMA Axiom, can look tenable only if a substantial amount of research published over the past five decades is left out of account. Consider, for example, the case of Subject-to-Object Raising, discussed on pp. 213f. of the book under review. The examples given are (3a) and $(3 \mathrm{c})$, analysed by Croft as $(3 \mathrm{~b})$ and $(3 \mathrm{~d})$, respectively:

(3) (a) I believe that he ate the bagel.

(b) I believe [that he ate the bagel]

(c) I believe him to have eaten the bagel.

(d) I believe [him] [to have eaten the bagel].

Croft's comment on this analysis is (p. 214):

In [(3b)], the object of believe is a Clause, which encodes the proposition that I believe. In [(3d)], we find instead two units, one of which is encoded as a Direct Object Noun Phrase, and the other as an Infinitival Predicate. An iconic analysis of the semantic structure for a Raising to Object construction would be that a belief can be construed here as ascribing a property (in the Infinitival Complement) to the Object referent of believe. In fact, Langacker gives just such an analysis (Langacker I995).

This comment is problematic from an interpretative point of view, in that it is not clear whether Croft does or does not subscribe to the 'iconic' analysis presented in Langacker (1995) (cf. the comment made in section 2 above regarding chapter 5). If he does, the following critique applies to his analysis. If he does not, it applies to the 'iconic' analysis presented by Langacker. But then it must be observed that Croft fails to propose his own analysis. One might perhaps infer from the subsequent text, especially p. 2I8,

Yet in a construction grammar without syntactic relations, it is again straightforward to map the argument phrases of the construction's syntactic structure into the appropriate participant roles of the construction's semantic representation, on the model of Figure 6.4 


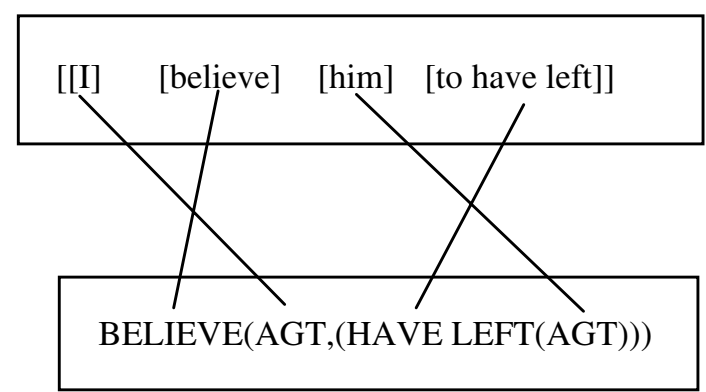

Figure 4

Possible RCG analysis of I believe him to have left

that Croft thinks of an analysis in terms of something like figure 4, which is an analog of his figure 6.4, reproduced above as figure I. But then, apart from its ad hoc character commented on above, the critique presented below still holds, as one will see.

The 'iconic' analysis proposed by Langacker suggests that there are at least two ways of construing a belief, one in which a belief is a relation between a believer and a proposition, as in ( $3 a, b)$, and one in which an infinitivally expressed property is ascribed to the object referent of the verb believe, as in (3c, d). One wonders if there are further construals for French, which does not have the construction exemplified in (3c) but does have, for example:

(4) (a) Je vous croyais malade.

(b) Je vous croyais à Paris

(c) Je vous croyais en retraite.
'I thought you were ill.'

'I thought you were in Paris.'

'I thought you were retired.'

By the same token, a belief should be construed here as ascribing an adjectivally or prepositionally expressed property to the object referent, where the terms 'adjectival' and 'prepositional' are strictly language-specific (note that the French prepositional phrase en retraite is expressed in English as the adjective retired). Clearly, this procedure makes such 'iconic' construals dependent on the grammar and lexicon of the language in question, which is bound to reduce their value for any semantic purpose.

The main argument against this analysis, however, lies in the obvious fact, argued for at length in numerous publications since at least 1960, that the object-NP in a sentence like (3c) has a double status. In the syntax of surface structure, it is just the direct object of the verb believe, but AT A DIFFERENT, DEEPER, LEVEL OF ANALYSIS it is the syntactic, and in this case also the semantic, subject of the verb have eaten. This deeper level is closer to the level of semantic description but not necessarily identical to it, since the embedded clause must likewise be reduced to its deepest form, and so on till all 
embedded S-structures have been reduced. The final result of the reduction process is regarded as the semantic analysis of the sentence concerned. Conversely, given a semantic analysis of a sentence, there is an S-cyclic process of transforming each $\mathrm{S}$ (clause) to its surface form, starting from the most deeply embedded $\mathbf{S}$ till the highest $\mathrm{S}$ has been processed. It is the semantic analysis of a sentence, not its surface structure, that is considered semantically regular and transparent. Given the difference between the two levels of representation, a nontrivial algorithmic computational system is required mapping semantic analyses onto surface structures and/or vice versa. This is the essence of all theories of grammar of the more or less recent past, except those that have issued from the 'cognitivist' camp, where any notion of computational construction-meaning mapping is rejected and where one tries to make do with what in effect is the limiting case of a one-toone construction-to-meaning computation, which is so simple that the term COMPUTATION can be avoided.

The most extensive study of cases like (3a-d) is Postal (1974), a well-known publication but not mentioned by Croft. Postal shows, with an impressive array of arguments, first, that him in (3c) is indeed, at surface level, the direct object of believe. This conclusion is already well-nigh inescapable in caseassigning languages that have the Subject-to-Object Raising construction, such as Latin, where (3c) would correspond to Credo eum bagellum edisse with eum 'him' in the accusative case (I invent the word bagellus or, if you like, bagellum, for 'bagel'). But within the confines of English, the following is among Postal's most convincing arguments for this first point (Postal I974: 4I3). The English verbs figure out or find out occur in sentences like (5a-c) but $\operatorname{not}(5 \mathrm{~d})$.

(5) (a) I figured the man out to be a swindler.

(b) I figured out the man to be a swindler.

(c) I figured him out to be a swindler.

(d) *I figured out him to be a swindler.

This pattern is identical to what is found normally in cases of a verb together with a verbal particle, where full lexical object-NPs are free to occur before or after the particle, but pronominal object-NPs have to come before the particle, as in (6). ${ }^{7}$

[7] This argument is particularly damning for the analysis upheld in Chomskyan circles for a few decades, assigning grammatical subject-status to the surface object constituent and assuming 'Exceptional Case Marking' giving oblique case to that constituent. This analysis, however, was given up in Chomsky (I995: I74): 'Exceptional case marking by V is now interpreted as raising of NP to the Spec of the AgrP dominating V. It is raising to [Spec, $\mathrm{Agr}_{\mathrm{o}}$ ], the analogue of familiar raising to [Spec, $\mathrm{Agr}_{\mathrm{s}}$ '. The esoteric terminology will not disguise the fact that Chomsky now accepts Subject-to-Object Raising as a valid rule of grammar, the analogue of Subject-to-Subject Raising. 
(6) (a) I rang the man up.

(b) I rang up the man.

(c) I rang him up.

(d) *I rang up him.

This, together with a host of other observations, should convince any reasonable person that ${ }_{\mathrm{NP}}\left[\right.$ the man] in (5a) and (5b), and analogously ${ }_{\mathrm{NP}}[\mathrm{him}]$ in (3c) and (5c), do indeed have the syntactic status of a direct object in the sentences as they stand.

Further distributional facts, however, impose the generalization that the object-NP in such sentences fulfils the role of syntactic subject, but not necessarily also of semantic subject, to the embedded verb at a deeper level of analysis. This appears from sentences like (7a), (7c) or (7e), where the dummy words it and there and the NP the man correspond regularly with the same words in the position of syntactic subject in the corresponding sentences (7b), (7d) and (7f), respectively. One notes that the semantic subject of the latter three sentences is not it, there, or the man but rather that Harry won the race, the problem of Julian's illness, and for the man to agree, respectively.

(7) (a) I take it to be true that Harry won the race.

(b) It is true that Harry won the race.

(c) I take there to be still the problem of Julian's illness.

(d) There is still the problem of Julian's illness.

(e) She reckons the man to be likely to agree.

(f) The man is likely to agree.

Clearly it makes no semantic sense to read the sentences (7a) and (7c) as saying that the speaker ascribes a property to it, or to there. And if it APPEARS to make sense to say that the person denoted by she ascribes the property of 'being likely to agree' to the man in question, that is only an illusion, fostered by the fact that English likely induces Subject Raising. If it were not an illusion, then there should also be a property of 'being probable to agree', which does not sound right, precisely because probable does not induce Subject Raising.

In fact, on p. 2I4, Croft falls victim to precisely this illusion:

It is plausible to analyze the semantic interpretation of ( $14 \mathrm{~b})$ [ = Tina is hard to find] as attribution of the complex predicate denoted by be hard to find to the Subject referent.

One notes that here it is not the PROPERTY but the PREDICATE 'be hard to find' that is said to be attributed to the subject referent. Whereas one may agree that 'be hard to find' can be construed as a complex PREDICATE by means of lambda-abstraction from It is hard to find Tina (a method of construal that is unlikely to carry Croft's approval), one would be hard put to maintain that all such lambda-abstracted complex predicates are stored in memory as 
properties, which would make them concepts. Yet that is what Croft's theory requires.

And how about a complex predicate like be madness to blame? This 'complex predicate' is likewise constructible by lambda-abstraction from 'It is madness to blame Tina', but that abstraction is not allowed by the grammar of English, as *Tina is madness to blame is unlikely to be accepted as a good English sentence, which makes any alleged property or concept of 'being madness to blame' vanish into thin air. It seems sensible to dispatch any alleged concept or property of the type 'be hard to find' in the same direction, unless it is clearly demonstrated that it has indeed been stored in memory, for example under the label of a lexical item. But it is not good method to rely on English grammar for the definition of concepts.

Finally, when there are no syntactic-subject complications intervening in the embedded clause, the surface object-NP corresponds to the semantic subject-NP of the embedded clause, as appears unambiguously from cases involving idioms or fixed collocations, such as those in (8).

(8) (a) She didn't expect the penny to drop so soon.

(b) She hadn't expected time to be up so soon.

(c) She expected all hell to break loose.

(d) She knew the game to be up.

Clearly it makes no semantic sense, in the cases $(8 a-c)$, to construe an expectation as a mental prediction of the adherence of the property of 'dropping so soon' to any particular penny, or of 'being up so soon' to time, or of 'breaking loose' to all hell. Nor does it make sense to read (8d) as saying that her knowledge assigned the property of 'being up' to any game in question. But it does make sense to read $(8 \mathrm{a}-\mathrm{c})$ as saying that the object of her expectation, in each case, was whatever is the interpretation of the expressions the penny dropped, time was up, and all hell broke loose, respectively, and to read (8d) as saying that what she knew is what is expressed by the idiom the game is up. It should, therefore, be clear that the analysis of the Subject-to-Object Raising construction proposed by Langacker and others is simply untenable. It should likewise be clear that if the intended RCG analysis of this construction runs along the lines of figure 4 above, any such analysis is likewise untenable, if only because of the facts quoted in (5)-(8) above.

In order to be better able to account for complications in the mapping of form onto meaning or vice versa, RCG dilutes the notion of syntactic construction by stripping it of syntactic relations and of all kinds of formal markers. Yet even with such a weak notion of syntactic construction, the phenomena cannot be accounted for in a principled and systematic way. The main point is that if one is forced to drop the ICMA Axiom as a basis for a grammatical system, some other system is required to account for the data, which will be even further removed from the one-form-one-meaning principle. Over the past fifty years a variety of systems have been proposed, some 
of which contain great promise, which reject the ICMA Axiom and thus also its stronger versions. But all of these proposals have in common that they involve, one way or another, a computational, algorithmic machinery of much greater complexity than the simple one-to-one construction-meaning mapping posited in the ICMA Axiom. This again makes it impossible, at least for those theories that look beyond the mere computational aspects and take a realist-mentalist view, to treat any system that maps meaning onto form or vice versa as part of the conscious mind, open to awareness and analysable by introspection. It becomes necessary, instead, to regard the mental form-meaning mapping system for natural language, or, as we now say, linguistic competence, as an autonomous bit of machinery, closed to awareness, inaccessible to introspection and not to be shared in commonsensitivity sessions.

In other words, linguistic competence is regarded as a cognitive module, described in general terms as a cognitively insulated 'subsystem having a well-defined set of inputs, a well-defined set of outputs, and a well-defined relation between inputs and outputs' (Arbib 1987: 334$).{ }^{8}$ It is nowadays widely agreed that the human mind contains a large number of modules, or processing units, which are rapid, automatic, cognitively inaccessible, domain-specific input-output routines. Linguistic competence is regarded as being one of them, mapping semantic structures onto surface structures and/ or vice versa. ${ }^{9}$

The system that does the mapping for a language $\mathbf{L}$ is usually called the grammar of $\mathbf{L}$. A grammar contains RULes for the (de)composition of sentences, and constructions are accordingly seen as being defined by those rules. It is remarkable, to say the least, that not only Croft but also his associates in Cognitive Grammar and Construction Grammar write as if there were no notion of modularity around. The notion of (constructive or analytical) RULE is never mentioned in the book under review, although it is constitutive of the 'formalist' concept of grammar which the author rejects (and feebly criticizes). ${ }^{10}$ Instead, there is, in the writings of the schools in question, a general trend to fall back on old taxonomic notions of structure, now linked up with a view of the human mind that was current a century ago and had no room for algorithmic modular routines that go their own way

[8] A particular and widely discussed form of modularity is presented in Fodor (I983); see also chapter 2 in Seuren (200I).

[9] It is, of course, no coincidence that the view of the mind as a system containing a number of 'underground', modular subsystems came about in the period in which computers began to be developed. The notion of grammar as an algorithm acquired its enormous popularity in the context of the 'cognitive revolution' of the 1960s, which wiped behaviourism off the map and replaced it with the computational view of the mind.

[Io] Remarkably, Croft still uses the names of rules he rejects to characterize certain constructions, such as 'Raising to Object' (p. 213: 'a construction that I will call by its transformational name'), or 'Gapping' or 'Right Node Raising' (p. 189). 
once set into motion. The result is a born-again structuralism resuming American notions of structure that were current until about I950, and a traditional European concept of mind. ${ }^{11}$ When use is made of MODERN results of cognitive psychology, it is always in areas of the human mind where experiences are felt and can be commented upon, and never in those areas that are inaccessible to introspection, such as the much-studied internal organization of the mental lexicon and its auxiliary machineries of active and passive retrieval.

Why this wholesale rejection, and ignoring, of the modularity view of grammar, of anything to do with formal rules that are part of a self-contained computational system? And why, in a similar vein, the horror of anything to do with formal semantics, or logic, or even philosophical analysis of meaning - all of which cognitivists or typologists won't touch with a barge-pole? One might think of Ockham's razor: 'do not complicate the theory beyond necessity'. But, clearly, when it has been SHOWN TO BE NECESSARY to complicate the theory but nothing is done about it, the razor cuts into the flesh. Behaviourism succeeded in keeping psychological theory restricted to stimulus-response associations until it was SHOwn that that degree of simplicity would stifle any attempt at a causal explanation of human behaviour. Accordingly, behaviourism was replaced with what is now known as Cognitive Science. In similar fashion, it has been shown, over the past five decades, that some form of indirect, computation-driven, form-meaning mapping is necessary for natural language sentences. And accordingly, the old structuralism made way for computational grammatical theories. So the question is again: what makes the cognitivists baulk at any form of computation, whether logical or grammatical, and revert to the old, inadequate paradigm?

It must, regrettably, be admitted that the modularity view, as it has developed since the I95Os in the context of generative grammar, has been sadly disappointing, to the point even of offending many hard-working, sensible and decent linguists' sense of dignity. In a recent article, Langendoen puts his finger just beside the sore spot (Langendoen 2002: 642):

The increasing popularity of functionalist theories, and the return of empiricism in several parts of the field, especially psycholinguistics and computational linguistics, indicates widespread dissatisfaction with recent

[II] It is almost amusing to see how Croft lapses into formulations that could have been taken straight out of a German philosophy text of, say, the I930s, as on p. I28:

But conceptual structure ... is itself not a single resolvable structure. Instead, conceptual structure is an experience in which alternative, conflicting conceptualizations are simultaneously immanent.

One would have thought that the days when such formulations were current were long gone. 
developments in generative grammar. This is not to suggest that these responses are un- or anti-scientific. On the contrary, I suggest that several different 'sciences of language' may flourish under the umbrella of linguistics; that different subfields have different subject matter that requires different methods, theories and tools. Moreover, these can be combined in various ways, so that one can look at computational linguistics as requiring the use of both symbolic and statistical methods ..., and psycholinguistics as requiring both rules and habits ....'

It is undoubtedly true that recent developments in generative grammar have failed to satisfy many serious linguists, and for perfectly valid reasons (Seuren 2004). It is also true that there are many different types of causal questions that can be asked about natural language, each type requiring its own appropriate kind of method and theory. Computational linguistics and psycholinguistics are indeed good examples of disciplines engaged in finding answers to causal questions that are different from those asked in what is known as theoretical linguistics. But that does not seem to justify a general policy of ignoring vast amounts of convincing arguments and analyses presented over a period of decades WITHIN THE SAME SUBFIELD, in an effort to answer THE SAME CAUSAl Questions. And this is what we find here.

Attempts such as the one made in the book under review to escape from the consequences forced upon linguistic theory by the phenomena found in natural languages just do not work. Even when weakened to a version like the ICMA Axiom, such attempts remain unsuccessful. Any principle like the ICMA Axiom or its stronger versions must be replaced with a more sophisticated basis for construction-meaning mapping, Once that is recognized, any theorist of language who takes the grammar of a language to reflect speakers' linguistic competence is forced into a modular, computational, rule-governed view of grammatical processing, even if that means that the level of technical difficulty of the subject is stepped up considerably.

\section{German VERb-CLUSters and other problems}

In order to maximize the cogency of this point I will now apply a test that has, on several occasions, proved useful in the past as a diagnostic to see if particular theories have sufficient power to account for the facts of natural language in a principled way. The test is eliminative, in that a negative outcome is a sufficient reason for considering the theory as it stands inadequate, but a positive outcome is only a sufficient reason for not considering it inadequate at this stage. The test involves the phenomenon of VERB-CLUSTERING, which is found in the complementation system of a very large number of languages around the world and, in many cases, has disastrous consequences for anything similar to the ICMA Axiom. German and Dutch are languages where Verb-clustering is rampant and where it is most obvious that the 
ICMA Axiom runs aground. I will present the case of German Verb-clusters, as exemplified in the subordinate clause (9). ${ }^{12}$ The analysis and description are given here in terms of my theory of Semantic Syntax (Seuren 1996), but it must be mentioned immediately that remarkably successful treatments have also been proposed in terms of other theories, such as Categorial Grammar (e.g. Steedman I985; Moortgat I988; see Seuren \& Kempen 2003 for a variety of approaches to German and Dutch Verb-clusters). If anything does, cases such as (9) put Croft's RCG, as well as other varieties of Cognitive Grammar or Construction Grammar, to a crucial test. ${ }^{13}$

(9) daß er den Hund die Zeitung hat holen lassen wollen that he the $\mathrm{ACC}_{\mathrm{AC}}$ dog the $\mathrm{ACC}_{\mathrm{Caper}}$ has fetch let want 'that he wanted to get the dog to fetch the newspaper'

Note that hat 'has' expresses the present perfect tense of the infinitive wollen 'want', which lacks the expected past participle form, that er 'he' is, besides being the syntactic subject of the finite verb form hat, also the semantic subject of both wollen 'want' and lassen 'let, get to do', that den Hund 'the dog' is, though in the accusative case, the semantic subject, and die Zeitung 'the newspaper', likewise in the accusative case, the semantic object, of holen 'fetch'.

The clause looks like a hodge-podge of constituents devoid of any semantic coherence, the opposite of what one could possibly wish to call 'iconic'. The elements that belong together semantically are dispersed all over the sentence, sometimes with inappropriate morphological marking (accusative case for den Hund, which is semantic subject to holen), without any intonational unit showing them to be semantically associated, and without any information-structural factor overriding criteria of constructional unity. An intelligent and sympathetic listener who knows the German words but not the grammar of German will probably manage to reconstruct a plausible scenario that would accommodate the pieces. But that is not what the grammarian is after. Such a listener might come up, for example, with an interpretation corresponding to 'that he wanted the dog to let him get the newspaper', which is something clause (9) could not possibly mean (though

[12] It has become customary, in discussions of German and Dutch verb constructions, to use subordinate clauses, and not main clauses, as examples, the reason being that Verb-clusters remain intact in subordinate clauses, whereas they are split up into a finite and a non-finite part in main clauses.

[13] I would have preferred to use the following, more idiomatic, clause, whose derivation is equally straightforward in terms of Semantic Syntax:

(i) $\mathrm{da} ß$ er sich die Zeitung vom Hund hat holen lassen wollen that he himself $f_{\mathrm{DAT}}$ the $_{\mathrm{ACC}}$ paper by the $\mathrm{DAT}_{\mathrm{DAT}} \mathrm{dog}$ has fetch let want 'that he wanted to get the paper brought to him by the dog'

But even the briefest of descriptions of its derivation would have to take up more space than would be acceptable given any reasonable sense of proportion. 
one can easily imagine the growling dog standing between the man and the newspaper). What sort of memory-stored, 'iconic' ICMA construction could this possibly be an instance of? If Croft is serious in claiming (p. 33) that RCG 'allows each language to be itself' and that 'it respects the grammatical diversity of languages, and the uniqueness of each language's grammar', then this is an ideal opportunity for him to show that he means business.

In actual fact, however, the structure of (9) is quite transparent, provided one allows either for a system of different levels of representation and topdown rules transforming an underlying semantic analysis (SA) into a corresponding surface structure (SS), or for a system of bottom-up functional applications, as in Categorial Grammar, or for some other well-defined computational system relating the two structural levels. Being versed myself in the variety of Transformational Grammar which I call Semantic Syntax, I will show in rapid outline the top-down mapping from the SA onto the SS as defined by Semantic Syntax (for a more complete description of this construction, see Seuren 1996: chapter 6, and Seuren 2003). But one should realize that an analogous bottom-up mapping is elegantly achieved in terms of, for example, Categorial Grammar, as shown, for example, in Steedman (1985) or Moortgat (I988).

In terms of Semantic Syntax, clause (9) and its countless cousins follow from a rule system that takes as input a standard SA and applies a handful of simple and solidly motivated transformational rules. The derivation goes as shown in (IOa-h).

The structure (Ioa) is the SA of clause (9), which is semantically regular and transparent, and to which one is welcome to apply the ICMA Axiom (though a more principled method of semantic interpretation seems preferable). Following McCawley (1970), the overall underlying constituent order is taken to be Verb-Subject-(Indirect Object)-(Direct Object), or V-S-O in established terminology. Those predicates (verbs) that are listed in the Lexicon as inducing one or more cyclic transformational rules are marked for those rules in the tree structures by means of the rule names in angled brackets. These rules apply S-cyclically from the bottom upwards. To help the reader follow the process, the cyclic rule that is up for application in each case has been marked with an arrow.

The rule Predicate Raising (PR), which is lexically associated with lassen on the $\mathrm{S}_{4}$-cycle, must apply first. PR consists in the detachment of the Verbconstituent of the embedded $\mathrm{S}$ and its re-attachment to the inducing Verb by means of a process of Adoption (Seuren 1996: 55f.). The S5-node now disappears, given the general principle:

An S, or / S (see below), that loses its Verb is eliminated.

All material depending on $\mathrm{S}_{5}$ is re-attached, in the order given, to $\mathrm{S}_{4}$. The result is shown in (Iob). Note that German Verb-clusters are, in principle, 

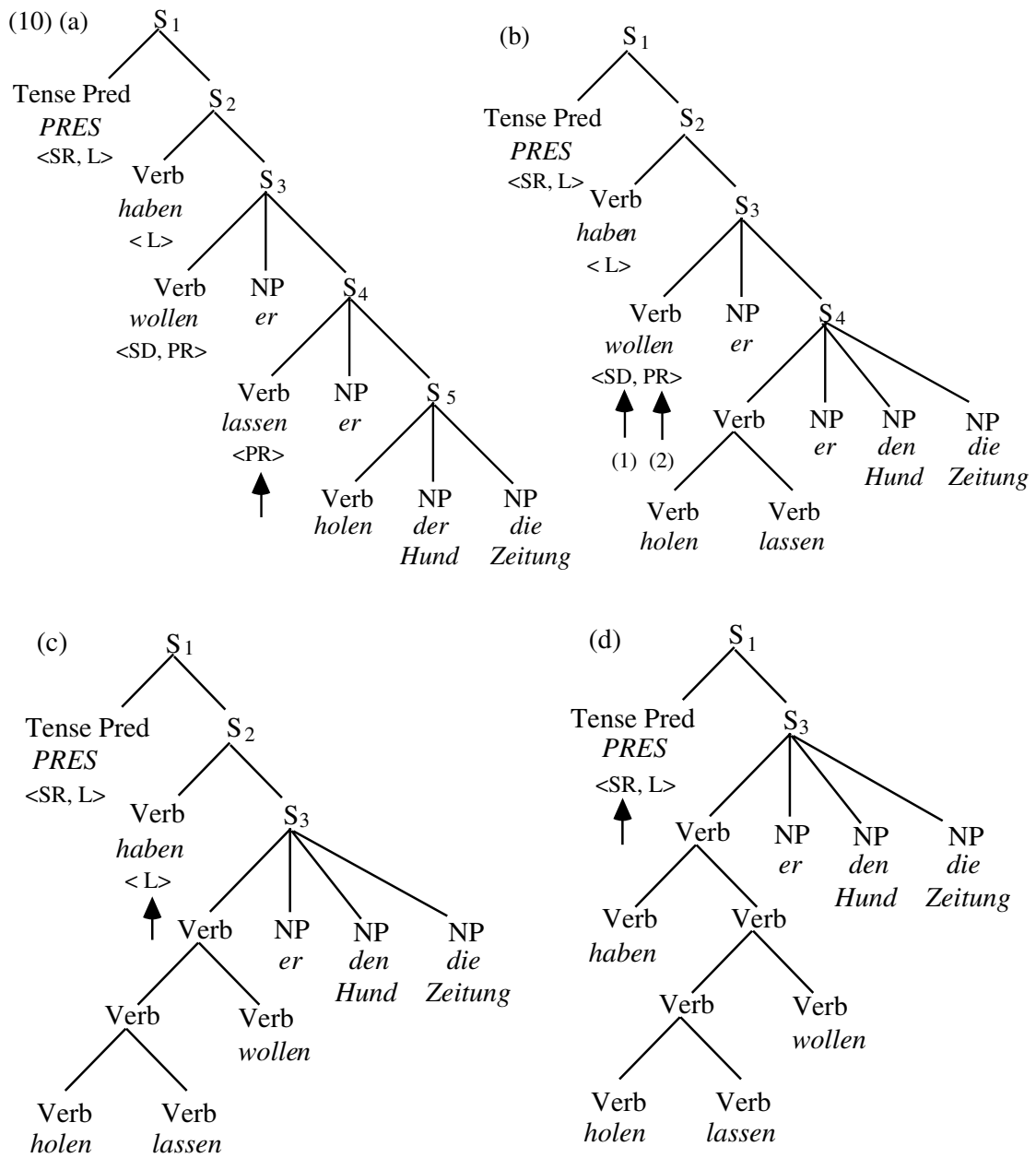

left-branching (as in Turkish, Japanese, Aztec, Yaqui, Luiseño ${ }^{14}$ and other languages), which means that when a lower verb is adopted it ends up to the left of the higher adopting verb. Only in some cases, to be discussed in a moment, does German turn to right-branching in Verb-clusters. (In Dutch, French, Italian, Spanish, Malay and other languages, Verb-clusters are in principle right-branching.)

[I4] As for Aztec, Yaqui and Luiseño, see Langacker (I973). On p. 489 of that paper, Langacker says:

Predicate Raising would be included in the inventory of rules with which human children are innately endowed. It will not necessarily be the case that every language will make use of every rule in this inventory; a given language will select a subset of these rules. 

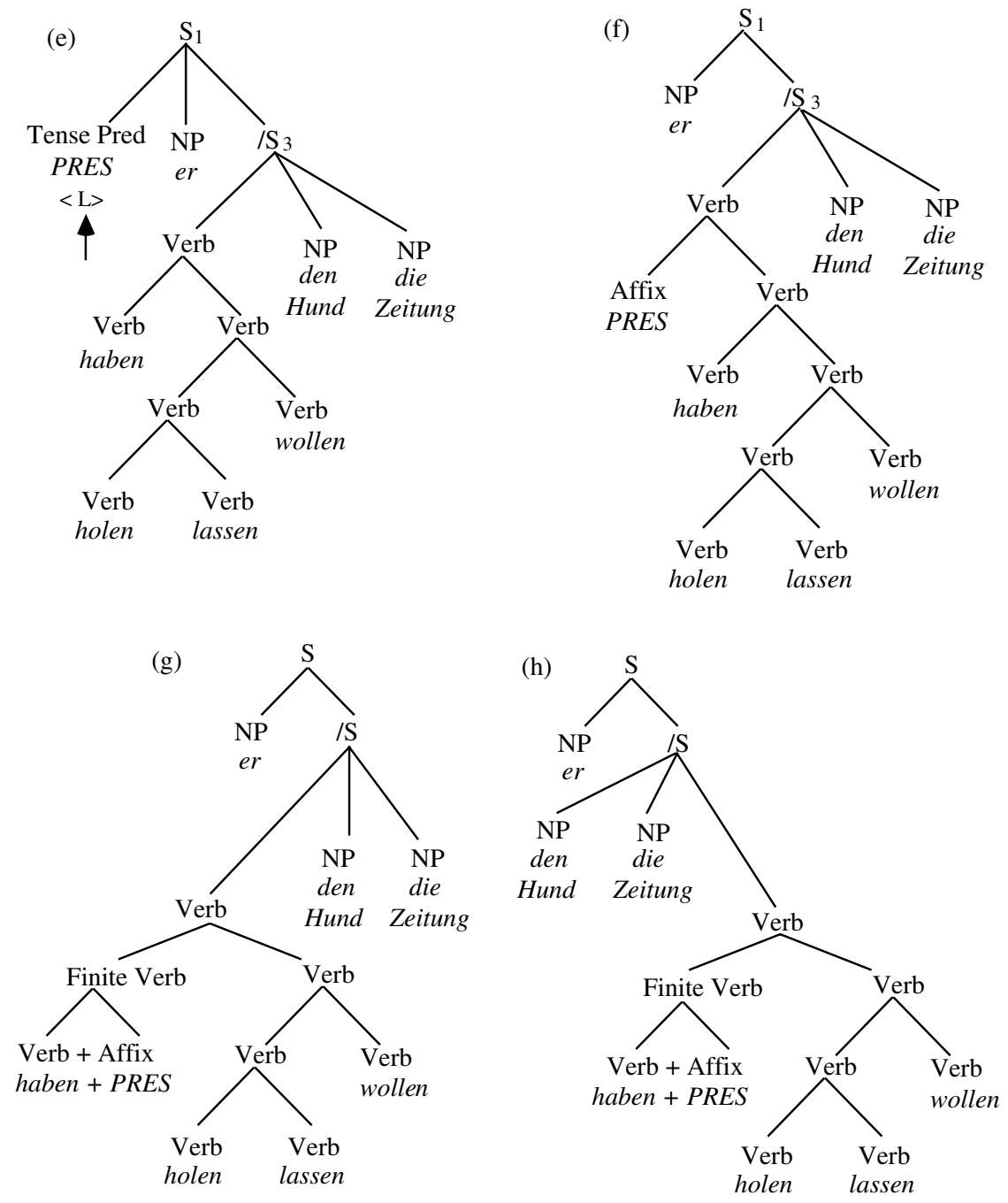

The old subject-NP der Hund changes case from nominative to accusative, as German systematically assigns accusative case to subject-NPs raised as a result of PR. ${ }^{15}$ (The assumption is that case is assigned PRIMARILY according to instructions given in the lexicon for the controlling verb, and SECONDARILY

[I5] In many Predicate-Raising languages the lower subject is assigned derived accusative case when the embedded object clause is intransitive, but dative case when the embedded object clause is transitive. In fact, such datives are an important diagnostic for Predicate Raising in the languages in question. 
as a result of changes in structural position owing to transformational processes.)

The next rule up for application is Subject Deletion (SD) on the $\mathrm{S}_{3}$-cycle, induced by the verb wollen. SD deletes the subject-NP of the complement-S under condition of coreferentiality with a controlling NP-term in the higher clause. In most cases, as also here, the controlling NP-term is itself the subject of the higher clause. There is a second general principle:

An $\mathrm{S}$ that loses its subject-NP is demoted to /S ( $\mathrm{S}$ without subject-NP), the equivalent of the well-known Verb Phrase (VP).

Then PR applies again, likewise induced by wollen. The result is shown in (IOC).

We have now arrived at the $\mathrm{S}$-cycle, where the rule Lowering (L) applies, induced by the perfective auxiliary verb haben (have). This rule detaches the inducing verb, which is adopted by the Verb-constituent of the embedded S. Since the S-node dominating the lowered verb now only dominates another $\mathrm{S}$, it has become otiose. Therefore, it is pruned and disappears from the structure.

One would expect verb[haben] to follow the left-branching directionality of German Verb-clusters and thus to be placed on the right-hand side above the adopting Verb-cluster of $S_{3}$. Yet, as one sees from (Iod), this does not happen: verb $[$ haben] is placed on the left-hand side above the lower Verb-cluster, thereby creating a right-branching directionality. This phenomenon, which we call the R-Condition but which is known in German grammar as OBERFELDUMSTELLUNG, occurs obligatorily when the perfective auxiliary haben is lowered onto a Verb-cluster whose highest, i.e. rightmost, verb is one of the so-called R-CLASS (see Seuren I996: 273):

$\begin{array}{llll}\text { sehen 'see' (optional) } & \text { können 'be able' } & \text { mögen 'like, may' } \\ \text { hören 'hear' (optional) } & \text { müssen 'must' } & \text { dürfen 'be allowed' } \\ \text { fühlen 'feel' (optional) } & \text { sollen 'must' } & & \\ \text { lassen 'let, allow, make' } & \text { wollen 'want' } & \end{array}$

\section{$R$-Condition}

When a verb from the R-class is the highest (rightmost) verb in a cluster and the cluster stands directly under the perfective auxiliary haben, there is a switch in branching directionality from left to right: from here on, all subsequent lowerings onto the Verb-cluster will be right-branching. Moreover, when this happens, the main verb is not turned into a Past Participle but remains infinitival, the so-called Ersatzinfinitiv.

Having dealt with the Lowering of verb[haben] we have arrived at (Iod). The next rule up for application is SUbJect RaISING (SR), induced by the tense predicate PRES. SR consists in detaching the subject-NP of the dependent clause and placing it in the position of its dominating S-node. The 
latter is moved one position to the right and demoted to the status of $/ \mathrm{S}$ (=VP), according to the second general principle formulated above. This gives (Ioe).

The last cyclic rule to apply is, again, Lowering, likewise induced by the tense predicate PRES. Owing to the R-CONDITION forced by the earlier lowering of haben, PRES is placed on the left-hand side above the existing Verb-cluster. In the process, the categorial labelling of PRES is changed from 'Tense Predicate' to 'Affix', according to the principle that surface categories are assigned during the transformational process. The result is (Iof), which is the structure of clause (9) at the end of the Cycle. Note that the original $\mathrm{V}-\mathrm{S}-\mathrm{O}$ order of main constituents has now changed into $\mathrm{NP}-$ / $\mathrm{S}(=\mathrm{VP})$.

Two postcyclic rules (which are, on the whole, less universal and more language-specific than the cyclic rules) do some final trimming and prepare the structure for the morphological component. First, a postcyclic rule of AfFix Handuing makes the verb directly under an Affix right-adopt the Affix, thereby creating a morphological word unit. The resulting $\mathrm{VERB}+$ AfFIX construction corresponds to the finite verb form in SS. This stage of the derivation is represented by ( $\mathrm{Iog})$. A second postcyclic rule, V-FInAL, moves the entire Verb-cluster to the far right. (In German and Dutch, V-Final moves the entire Verb-cluster to the far right in non-main clauses, but only the non-finite part of the Verb-cluster in main clauses, leaving behind the VERB + AFFIX word unit that will be the finite verb form in SS.) At this moment, we have arrived at the structure (Ioh), which is ready to be fed into the morphological component, which will produce the surface structure of clause (9).

The least one can say of this derivation is that it is clear and explicit, and produces the desired result. I also believe it to be correct, at least in principle, but I am happy to leave that judgment to others. The point is that SOME SUCH TREATMENT is needed to account for both the grammar and the semantics of a clause like (9), and that NO SUCH TREATMENT can conform to the ICMA Axiom. The case of clause (9) is thus put forward as a challenge to Croft or any other adherent of the ICMA Axiom or any of its stronger versions.

It is relevant, in this context, to point out that a derivation such as the one shown above not only analyses and describes the clause in question in a precise and falsifiable way, but also fits into a system of generalizations not just about German and closely related languages, but about language in general, so that one is justified in claiming some, perhaps considerable, explanatory value for the approach as a whole. The system in terms of which the derivation in question is carried out allows for the language-universal generalization that languages with an infinitival complementation system fall into three categories, those that have exclusively SR (such as English, Latin, Portuguese and many others), those that have exclusively PR (such as 
German, Dutch, Turkish, Uto-Aztecan, Tagalog and many others), and those that have both (such as French, which has SR for subject complement clauses, but PR for object complement clauses) ${ }^{16}$ The contrast with RCG is striking. RCG rejects any constructional universals (p. 362: 'virtually all aspects of syntactic structure are language-specific, indeed, constructionspecific'), and it rejects the notion 'rule of grammar', thus blocking the way to the formulation of language universals in terms of rule systems, although that is where language universals stand out most clearly. One of the things I hope to have shown is that such self-imposed restrictions are a serious obstacle to a better understanding of the universal features of human language.

There are, of course, many other cases where the ICMA Axiom appears problematic. To take just a few examples, consider the cases (IIa-d).

(II) (a) The first American landed on the moon in 1968.

(b) Not until four o'clock did she post the letter.

(c) 'E ain't never been no good to no woman, not never.

(d) Me-de aburow mi-gu msu-m.

I-take the corn I-flow water-in

'I poured the corn into the water (to wash it).'

(Akuapem-Akan; Schachter 1974: 258f.)

In (IIa), one wonders who could possibly be denoted by the phrase the first American. To get the right interpretation one needs a semantic description of the word first and similar words involving a tacit element that can be rendered as the infinitival phrase 'to $\mathrm{X}$ ', where $\mathrm{X}$ is a variable ranging over propositional functions. To find the correct value of the variable $\mathrm{X}$ in each case is likely to be a rather complicated matter requiring quite a bit of formal calculus, which, to my knowledge, has not so far been provided in the more formally oriented quarters of semantic studies.

Sentence (IIb) is problematic as it does not mean 'it is not the case that until four o'clock she posted the letter', which is what the surface form of the sentence suggests. The sentence, moreover, requires Subject-AUX Inversion of the type also found in, for example (I2a) below, where, however, Subject-AUX Inversion is not obligatory, as is shown by (I2b). But (I2a) and (I2b) clearly differ in meaning, as any competent speaker of English knows (but not a listener with poor English, whose comprehension consists in guesswork).

(I2) (a) Only last summer did he make headlines (after years of trying).

(b) Only last summer he made headlines (and now he is dead).

[I6] See Seuren (1972) and Seuren (2004) for ample comment. 
It is unclear how any theory based on the ICMA Axiom would account for such phenomena. It is unclear in particular how any such theory could possibly isolate a constituent AUX in such a way that the dummy verb do emerges as its lexical carrier under certain conditions. This has been done elegantly and convincingly in a variety of computational theories, all of which, however, are incompatible with the ICMA Axiom.

The sentences (IIC) and (IId) above are instances of what is known as Copying or Spreading. One sees a rampant form of Negation Copying in (IIc), taken from the mouth of a Cockney speaker. One should note that this form of Negation Copying is far from simple, as it is bound up with existential quantifiers and negative polarity phenomena. In standard English, the sentence corresponds to the rather less colourful (I3), with any and ever instead of no and never.

(13) He hasn't ever been any good to any woman, not ever.

(IId) is a splendid example of Subject Copying in Akuapem, a dialect of the West African language Akan (observed by Schachter 1974: 258f.). The sentence contains the Serial Verb Construction gu msu-m ('flow into the water') and is especially interesting because a naive listener might well think that the sentence meant 'I took the corn and flowed into the water'. But it doesn't. It means what is given in the final translation line of (IId). All that happened to the sentence, after the normal deletion of the semantic subject of the embedded serial verb, allowed for by referential identity with aburow ('the corn'), is a copying of the pronominal subject of the main verb onto the embedded verb. The ICMA Axiom must indeed have magical powers if it allows for an adequate treatment of (IId).

\section{CONCLUSION}

To sum up, my general claim is that grammatical theories such as the one envisaged by Croft or by proponents of Cognitive Grammar or Construction Grammar, based on the ICMA Axiom or any stronger version of it, rejecting the modular, computational view of grammar and semantics, and relying essentially on general, non-specialized notions of cognition and perception, leave out of account a mass of well-publicized arguments put forward over the past half-century, as well as large classes of well-known, reliable data that served to support those arguments. Such theories have little choice but to fall back, on the one hand, on a view of the human mind that was current (in Europe at least) until the advent of modern Cognitive Science and had no place for autonomous, cognitively inaccessible modules, and, on the other hand, on forms of American structuralist grammar that are now, on the basis of detailed arguments, considered woefully inadequate for the grammatical description of languages. Despite the dissatisfaction that many linguists have justifiably felt with recent developments in generative grammar, overarching 
standards of good scientific method would have to override such feelings of dissatisfaction. One should be able to stick to good method while rejecting the aberrations of earlier attempts.

Then, besides my general claim, I have presented one particular case, the German clause (9), which, I believe, shows with extraordinary clarity the sort of data and the sort of argument that have led to the modularity view of linguistic competence, a view that requires specialized non-trivial algorithmic computation and is incompatible with the notion of grammar as part of general psychology.

\section{REFERENCES}

Antal, László (1964). Content, meaning, and understanding (Janua Linguarum, Series Minor 3I). The Hague: Mouton.

Arbib, Michael A. (1987). Modularity and interaction of brain regions underlying visuomotor coordination. In Garfield, Jay L. (ed.), Knowledge representation and natural language understanding. Cambridge, MA: MIT Press. 333-363.

Chomsky, Noam (1957). Syntactic structures. The Hague: Mouton.

Chomsky, Noam (1995). The Minimalist program. Cambridge, MA: MIT Press.

Croft, William (2000). Explaining language change: an evolutionary approach. Harlow: Longman.

Dryer, Matthew (1997). Are grammatical relations universal? In Bybee, Joan, Haiman, John \& Thompson, Sandra A. (eds.), Essays on language function and language type. Amsterdam \& Philadelphia: Benjamins. II5-I43.

Fodor, Jerry A. (1983). The modularity of mind. Cambridge, MA: MIT Press.

Goldberg, Adele E. (1995). Constructions: a Construction Grammar approach to argument structure. Chicago: The University of Chicago Press.

Harris, Zellig S. (I95I). Methods in structural linguistics. Chicago: The University of Chicago Press.

Langacker, Ronald W. (1973). Predicate Raising: some Uto-Aztecan evidence. In Kachru, Braj B., Lees, Robert B., Malkiel, Yakov, Pietrangeli, Angelina \& Saporta, Sol (eds.), Papers in honor of Henry and Renée Kahane. Urbana, Chicago \& London: University of Illinois Press. 468-49I.

Langacker, Ronald W. (1987). Foundations of Cognitive Grammar, vol. I: Theoretical prerequisites. Stanford: Stanford University Press.

Langacker, Ronald W. (I99Ia). Foundations of Cognitive Grammar, vol. II: Descriptive application. Stanford: Stanford University Press.

Langacker, Ronald W. (I99Ib). Concept, image, and symbol: the cognitive basis of grammar. Berlin: Mouton de Gruyter.

Langacker, Ronald W. (I995). Raising and transparency. Language 7I. I-62.

Langendoen, D. Terence (2002). Linguistics at the beginning of the 2Ist century. Journal of Linguistics 38. 627-643.

McCawley, James D. (I970). English as a VSO language. Language 46. 286-299.

Moortgat, Michael (I988). Mixed composition and discontinuous dependencies. In Oehrle, Richard T., Bach, Emmon \& Wheeler, Deirdre (eds.), Categorial grammars and natural language structures. Dordrecht: Reidel. 319-348.

Newmeyer, Frederick J. (2003). Grammar is grammar and usage is usage. Language 79. 682-707.

Postal, Paul M. (1974). On raising: one rule of English grammar and its theoretical implications. Cambridge, MA: MIT Press.

Schachter, Paul (1974). A non-transformational account of serial verbs. Studies in African Linguistics, Supplement 5. 253-270.

Sebba, Marc (1987). The syntax of serial verbs: an investigation into serialization in Sranan and other languages. Amsterdam: Benjamins. 


\section{REVIEW ARTICLE}

Seuren, Pieter A. M. (1972). Predicate Raising and dative in French and sundry languages. Ms., Magdalen College, Oxford. [Published as chapter 7 in Seuren 200I.]

Seuren, Pieter A. M. (1990). Serial verb constructions. In Joseph, Brian D. \& Zwicky, Arnold M. (eds.), When verbs collide: papers from the I99o Ohio State Mini-Conference on Serial Verbs (Working Papers in Linguistics 39). The Ohio State University Department of Linguistics, December 1990. I4-33. [Reprinted as chapter 20 in Seuren 200I.]

Seuren, Pieter A. M. (1996). Semantic Syntax. Oxford: Blackwell.

Seuren, Pieter A. M. (1998). Western linguistics: an historical introduction. Oxford: Blackwell.

Seuren, Pieter A. M. (200I). A view of language. Oxford: Oxford University Press.

Seuren, Pieter A. M. (2003). Verb clusters and branching directionality in German and Dutch. In Seuren \& Kempen (eds.). 247-296.

Seuren, Pieter A. M. (2004). Chomsky's Minimalism. New York: Oxford University Press.

Seuren, Pieter A. M. \& Gerard Kempen (eds.) (2003). Verb constructions in German and Dutch. Amsterdam \& Philadelphia: Benjamins.

Steedman, Mark (1985). Dependency and coördination in the grammar of Dutch and English. Language 6I. 523-568.

Wetzer, Harrie (1996). The typology of adjectival predication. Berlin \& New York: Mouton de Gruyter.

Author's address: Max Planck Institute for Psycholinguistics, PO Box 3 IO, 6500 AH Nijmegen, The Netherlands.

E-mail:pieter.seuren@mpi.nl 